Zhao, O., Gardner, L., \& Young, B. (2016). Behaviour and design of stainless steel SHS and RHS beam-columns. Thin-Walled Structures, 106, 330-345.

\title{
Behaviour and design of stainless steel SHS and RHS beam-columns
}

\author{
Ou Zhao ${ }^{* a}$, Leroy Gardner ${ }^{\mathrm{b}}$, Ben Young ${ }^{\mathrm{c}}$ \\ ${ }^{\mathrm{a}, \mathrm{b}}$ Dept. of Civil and Environmental Engineering, Imperial College London, London, UK \\ ${ }^{c}$ Dept. of Civil Engineering, The University of Hong Kong, Pokfulam Road, Hong Kong, China \\ ${ }^{*}$ Corresponding author, Phone: +44 (0)20 75946058 \\ Email: ou.zhao11@imperial.ac.uk
}

\begin{abstract}
Previous studies on stainless steel tubular section beam-columns have revealed shortcomings in established codified design methods. These shortcomings stem principally from inaccurate predictions of the bending and column buckling end points of the design interaction curves, where the bending moment end points are tied to the elastic or plastic moment capacities without considering strain hardening, while the column buckling end points are often overpredicted. Inaccuracies also arise due to the adopted interaction factors, which do not fully capture the structural response of the stainless steel members under combined loading. These observations prompted the present research, which is aimed at developing more efficient design rules for stainless steel tubular section beam-columns. In the presented design proposals, the deformation-based continuous strength method (CSM), allowing for strain hardening, was used to determine the bending moment capacities (i.e. the bending end points), while the column buckling strengths (i.e. the column end points) were calculated according to recently proposed buckling curves. Based on these more accurate end points, new interaction factors were derived following a comprehensive numerical simulation programme. The accuracy of the new proposals was assessed through comparisons against over 3000
\end{abstract}


experimental and numerical results. Compared to the current design standards, the new proposal yields a higher level of accuracy and consistency in the prediction of stainless steel square and rectangular hollow section (SHS and RHS) beam-column strengths. Use of the proposed interaction factors but with the Eurocode bending moment capacities and revised column buckling strengths as the end points was also assessed and shown to result in more accurate and less scattered strength predictions than the current Eurocode provisions. The reliability of the proposals has been confirmed by means of statistical analyses according to EN 1990, demonstrating its suitability for incorporation into future revisions of international design codes for stainless steel structures.

\section{Introduction}

Stainless steel is gaining increasing use as a construction material, rather than simply a decorative material, in a range of engineering applications, owing principally to its favourable mechanical properties, good ductility and excellent resistance against corrosion and fire. Given the high initial material cost of stainless steel, structural design efficiency is of primary concern. For the design of stainless steel tubular section members, although a number of design standards exist, the provisions were generally developed in line with the corresponding carbon steel design guidelines, without considering the distinctive nonlinear stress-strain characteristics of the material. This has been shown to yield inaccurate strength predictions for some types of stainless steel tubular section structural components, including stub columns [1-8], columns $[1,5-7,9-11]$, beams $[5,7-9,12-14]$ and beam-column elements [9,15-20], which has prompted research aimed at investigating the structural behaviour of these components and developing more refined design approaches. For example, advanced treatments for local buckling in stainless steel sections, including the continuous strength 
method (CSM) [21-26] and the direct strength method (DSM) [27,28], have been developed and shown to provide more accurate predictions of stainless steel cross-section resistances under compression, bending and combined loading. Revised column buckling curves for a wide range of stainless steel open and closed profiles have been proposed by Afshan et al. [29], based on a large number of experimental and numerical data, and shown to offer a better and more consistent representation of the true structural response of stainless steel columns than current codified provisions. The aims of the present paper are to study the global instability of stainless steel beam-columns and to develop more efficient design rules. Beamcolumns are structural members which combine the beam function of transmitting transverse forces or moments with the compression (or tension) member function of transmitting axial forces [30]. Their failure modes involve combined bending (generally in-plane for closed sections and out-of-plane for open sections) and column buckling. Current design codes, including the European code EN 1993-1-4 [31], American specification SEI/ASCE-8 [32] and Australian/New Zealand standard AS/NZS 4673 [33], as well as other recent proposals [34], employ interaction curves for the design of beam-column structural members, with the shape of the interaction curve defined by interaction factors, and the end points taken as the member strengths under the individual loading conditions. However, comparisons between these established design methods and experimental and numerical results $[9,15,16,19]$ have generally indicated significant disparities, as well as scatter, in the prediction of beam-column capacities.

The present paper focuses on the design of stainless steel square and rectangular hollow section beam-columns, though a wider study by the authors also includes other cross-section profiles, such as circular hollow sections and I-sections. The paper begins with a brief review and comparative analysis of current beam-column design methods, of which the strengths and 
limitations are highlighted. The methodologies for overcoming the identified shortcomings and for deriving new beam-column design proposals are then presented. The design proposals, with revised interaction factors, are underpinned by a comprehensive numerical simulation programme, involving geometrically and materially nonlinear analyses of imperfect structural elements (GMNIA). Finally, the accuracy and reliability of the proposals are assessed against over 3000 experimental and numerical results.

\section{Current design methods for stainless steel beam-columns}

\subsection{Codified beam-column design methods}

Current codified expressions for the design of stainless steel beam-columns under axial load plus uniaxial bending [31-33] follow the same basic format, as given by Eq. (1), in which $N_{E d}$ is the applied axial load, $M_{E d}$ is the maximum applied first order bending moment about the axis of buckling, $N_{b, R d}$ is the column member buckling resistances, $M_{b, R d}$ is the member bending resistance, taken in the absence of lateral torsional buckling, as is the case herein, as that of the cross-section $M_{c, R d}$, and $k$ is the interaction factor. There are, however, differences in the determination of the column buckling and bending moment resistances, which act as the end points of the design interaction curve, and in the interaction factors $k$, which define the shape of the design interaction curve. For the calculation of bending resistance, the European code allows use of the full plastic $M_{p l, R d}$, elastic $M_{e l, R d}$ and reduced elastic $M_{e f f, R d}$ moment capacities for Class 1 or 2, Class 3 and Class 4 cross-sections, respectively, while the American specification [32] and Australian/New Zealand standard [33] employ the inelastic reserve capacity provisions to determine the cross-section bending moment resistances. None of these methods accounts for the pronounced strain hardening exhibited by stainless steels 
though, and thus all lead to unduly conservative predictions, particularly for stocky crosssections. With regards to column buckling strength, the provisions of both the European code [31] and the American specification [32] were found to yield generally unsafe predictions, while the explicit method employed in the Australian/New Zealand standard [33] resulted in safe but slightly conservative column buckling strengths $[7,19]$. The interaction factors used in EN 1993-1-4 [31], SEI/ASCE-8 [32] and AS/NZS 4673 [33] $\left(k_{E C 3}, k_{A S C E}\right.$ and $k_{A S / N Z S}$, respectively) are shown in Eqs (2) and (3), where $\bar{\lambda}=\sqrt{A \sigma_{0.2} / N_{c r}}$ is the member nondimensional slenderness, in which $A$ is the cross-section area, $\sigma_{0.2}$ is the $0.2 \%$ proof stress and $N_{c r}$ is the elastic buckling load. Following comparisons with test and finite element (FE) results, it was concluded by Zhao et al. [19] that the EN 1993-1-4 and SEI/ASCE-8 design formulae generally lead to unsafe predictions for beam-columns with large axial compressive forces, but result in unduly conservative capacity predictions where bending effects are dominant. The Australian/New Zealand standard AS/NZS 4673 was also found to yield improved, but still rather scattered strength predictions, though with a reduced number of predictions on the unsafe side [19].

$$
\begin{aligned}
& \frac{N_{E d}}{N_{b, R d}}+k \frac{M_{E d}}{M_{b, R d}} \leq 1 \\
& 1.2 \leq k_{E C 3}=1+2(\bar{\lambda}-0.5) \frac{N_{E d}}{N_{b, R d}} \leq 1.2+2 \frac{N_{E d}}{N_{b, R d}} \\
& k_{A S C E}=k_{A S / N Z S}=1-\frac{N_{E d}}{N_{c r}}
\end{aligned}
$$

\subsection{Greiner and Kettler's method}

Greiner and Kettler [34] developed new interaction factors for stainless steel beam-columns of Class 1 and 2 cross-sections, based on the general format of the beam-column design 
formula (i.e. Eq. (1)) and the EN 1993-1-4 column buckling and bending end points. Values for the interaction factors were firstly back-calculated for a series of the numerical GMNIA results, by means of Eq. (4), and then represented by the simplified expression of Eq. (5). However, while the derivation procedure was sound, since the end points of the proposed interaction formula were still tied to the Eurocode column buckling and bending moment resistances, the developed interaction factors not only represented the interaction effects, but also compensated for the difference of the actual and predicted values of the end points, as acknowledged by Greiner and Kettler [34] and highlighted by Zhao et al. [19]. The beamcolumn strength predictions from the proposals of Greiner and Kettler [34] range from generally unsafe to unduly conservative, as the applied loading varies from pure compression to pure bending. This is similar to the predictions from the European code and American specification, though with reduced scatter [19].

$$
\begin{aligned}
& k=\left(1-\frac{N_{E d}}{N_{b, R d}}\right) \frac{M_{b, R d}}{M_{E d}} \\
& k_{G \& K}=0.9+3.5\left(\frac{N_{E d}}{N_{b, R d}}\right)^{1.8}(\bar{\lambda}-0.5) \leq 0.9+1.75\left(\frac{N_{E d}}{N_{b, R d}}\right)^{1.8}
\end{aligned}
$$

\section{Methodology for overcoming shortcomings in codified beam-column formulae}

Shortcomings in existing stainless steel beam-column design provisions include (i) inaccurate predictions of the end points of the interaction curves, where the bending moment end points suffer from being determined without considering strain hardening, while the column buckling end points are often over-predicted, and (ii) interaction factors that include a significant degree of compensation for the inaccurate end points and thus do not fully capture the structural response of stainless steel members under combined loading. Improved beam- 
column design rules are therefore sought firstly through the adoption of more accurate end points and secondly through the development of revised interaction curves, anchored to these new end points.

The continuous strength method (CSM) is a deformation-based design approach, allowing for strain hardening in the determination of cross-section compression and bending moment capacities [21-25]. The main characteristics of the CSM lie in the employment of a 'base curve' to determine the maximum attainable strain $\varepsilon_{c s m}$ for a given cross-section under the applied loading conditions, and the adoption of an elastic, linear hardening material model to enable design stresses greater than the $0.2 \%$ proof stress $\sigma_{0.2}$ to be achieved. The base curve is defined by Eq. (6), where $\varepsilon_{y}$ is the yield strain equal to $\sigma_{0.2} / E, \bar{\lambda}_{p}$ is the cross-section slenderness, calculated as $\sqrt{\sigma_{0.2} / \sigma_{c r}}$, in which $\sigma_{c r}$ is the elastic buckling stress of the crosssection under the applied loading conditions [35]. The CSM elastic, linear hardening material model, which features four material parameters $\left(C_{1}, C_{2}, C_{3}\right.$ and $\left.C_{4}\right)$, is illustrated in Fig. 1, with the strain hardening slope $E_{s h}$ determined from Eq. (7). The CSM material model parameter $C_{1}$ is employed in Eq. (6) to prevent over-predictions of strength from the linear hardening material model, with a value of 0.1 for austenitic and duplex stainless steels and 0.4 for ferritic stainless steel. The CSM material parameter $C_{2}$ is used in Eq. (7) to define the strain hardening slope $E_{s h}$, and is equal to 0.16 for austenitic and duplex stainless steels and 0.45 for ferritic stainless steel when $\varepsilon_{y} / \varepsilon_{u}$ is less than 0.45 ; when $\varepsilon_{y} / \varepsilon_{u}$ is greater than or equal to 0.45 , the strain hardening slope $E_{s h}$ is assumed to be zero. The parameter $\varepsilon_{u}=C_{3}(1-$ $\left.\sigma_{0.2} / \sigma_{u}\right)+C_{4}$ is the predicted strain corresponding to the material ultimate strength, where $C_{3}$ is equal to 1.0 for austenitic and duplex stainless steels and 0.6 for ferritic stainless steel; $C_{4}$ is equal to zero for all stainless steels. Note that Eq. (6) applies for cross-section slenderness values less than or equal to 0.68. The recently amended EN 1993-1-4 Class 3-4 slenderness 
limit of $c / t \varepsilon=37$ for internal compression elements corresponds to cross-section slenderness $\bar{\lambda}_{p}=0.65$ [24], where $c$ is the flat width of the compressive element in the cross-section and $\varepsilon=\sqrt{\left(235 / \sigma_{0.2}\right)(E / 210000)}$ is a parameter related to material properties. Thus, the CSM applies for all non-slender (Class 1,2 and 3) cross-sections, which are the focus of the present study.

$$
\begin{aligned}
& \frac{\varepsilon_{c s m}}{\varepsilon_{y}}=\frac{0.25}{\bar{\lambda}_{p}^{3.6}} \text { but } \leq \min \left(15, \frac{C_{1} \varepsilon_{u}}{\varepsilon_{y}}\right), \text { for } \bar{\lambda}_{p} \leq 0.68 \\
& E_{s h}=\frac{\sigma_{u}-\sigma_{0.2}}{C_{2} \varepsilon_{u}-\varepsilon_{y}}
\end{aligned}
$$

Based on the assumption of a linearly-varying through-depth strain distribution and the bilinear CSM material model, the CSM bending resistance for SHS and RHS $M_{c s m, R d}$ may be determined from Eq. (8), where $W_{e l}$ and $W_{p l}$ are the elastic and plastic section moduli, respectively, and $\gamma_{M 0}$ is a partial safety factor equal to 1.1 for stainless steel. Eq. (8) was found to yield substantially more accurate predictions compared to the codified elastic or plastic moment capacities [21-25]. Thus, the use of the CSM bending moment resistance as the end point in the numerical derivation of new interaction factors would substantially reduce the compensation effect. In addition, the CSM leads to consistent capacity predictions across the local slenderness range [21-25], which brings the possibility of deriving a single set of interaction factors for all non-slender cross-sections.

$$
M_{c s m, R d}=\frac{W_{p l} \sigma_{0.2}}{\gamma_{M 0}}\left[1+\frac{E_{s h}}{E} \frac{W_{e l}}{W_{p l}}\left(\frac{\varepsilon_{c s m}}{\varepsilon_{y}}-1\right)-\left(1-\frac{W_{e l}}{W_{p l}}\right) /\left(\frac{\varepsilon_{c s m}}{\varepsilon_{y}}\right)^{2}\right]
$$

Considering that current codified methods often over-predict the buckling resistance of stainless steel columns, Afshan et al. [29] derived revised buckling curves for a wide range of open and closed cross-section profiles by calibration against a comprehensive database of 
stainless steel test and FE results. For the design of SHS and RHS columns, the revised buckling curves adopt the same imperfection factor $\alpha=0.49$, as used in EN 1993-1-4 [31], but with shorter plateau lengths $\bar{\lambda}_{0}$, which are equal to 0.3 for austenitic and duplex stainless steels and 0.2 for ferritic stainless steel, compared to the current codified plateau length of 0.4 , as shown in Fig. 2. The proposed buckling curves were found to offer safe and accurate column buckling strength predictions [29], in contrast to the often over-predicted strengths determined according to the current codified provisions.

Thus, improved beam-column design rules may be sought through the use of the CSM bending moment capacity and the revised column buckling strength prediction as the end points and the subsequent development of new interaction factors. The proposed beamcolumn design formula is given in Eq. (9).

$$
\frac{N_{E d}}{N_{b, R d}}+k_{c s m} \frac{M_{E d}}{M_{c s m, R d}} \leq 1
$$

where $N_{b, R d}$ is determined according to the revised buckling curves described above [29] and $k_{c s m}$ is the proposed interaction factor, for which the derivation procedure follows that employed for carbon steel beam-columns [36,37], and may be summarised as follows:

(i) The cross-section sizes and material grades to be modelled were first selected. Two typical cross-sections, RHS $200 \times 100 \times 10$ and RHS $200 \times 100 \times 8$, which have been widely used in previous numerical studies of carbon steel and stainless steel beam-columns [34,36,37], are chosen in the present numerical simulations, and all three common families of stainless steel - austenitic, duplex and ferritic are considered.

(ii) For each modelled cross-section, the CSM bending moment resistances $M_{c s m, R d}$ about both major and minor axes were calculated. 
(iii) For each buckling axis of the modelled cross-sections, 15 beam-column lengths were selected to cover a wide spectrum of member slenderness $\bar{\lambda}$ between 0.2 and 3.0 , and the corresponding column buckling strengths $N_{b, R d}$ were determined according to the new buckling curves [29].

(iv) Beam-column FE models with the member lengths chosen in Step (iii) were developed, and subjected to a range of ratios of applied axial load-to-bending moment, from which the FE failure loads $N_{E d}$ and $M_{E d}$ were determined.

(v) Values for the interaction factors $k_{c s m}$ for each member slenderness $\bar{\lambda}$ and axial compressive load level $n=N_{E d} / N_{b, R d}$ were then calculated according to Eq. (10), which is a rearrangement of Eq. (9).

$k_{c s m}=\left(1-\frac{N_{E d}}{N_{b, R d}}\right) \frac{M_{c s m, R d}}{M_{E d}}$

(vi) The calculated interaction factors $k_{c s m}$ were plotted against the member slenderness for each load level $n$, and simplified formulae were fitted to the assembled data.

Development of the numerical models is outlined in Section 4, while derivation of the interaction factors, following the above procedure, is carried out in Section 5.

\section{Numerical modelling}

The present numerical modelling programme was performed using the nonlinear finite element analysis package ABAQUS [38]. Numerical simulations were carried out on single span pin-ended stainless steel RHS beam-columns, accounting for initial geometric imperfections and residual stresses, with the member slenderness ranging between 0.2 and 3.0. A detailed description of the development of the beam-column FE models and their 
validation against experimental results were presented by the authors in previous studies $[18,19,26]$ of stainless steel structural elements under combined axial load and bending moment, so only the key relevant aspects of the modelling are reported herein.

The four-noded doubly curved shell element with reduced integration and finite membrane strain, S4R [38], which has been used successfully in previous studies $[18,19,26]$ concerning the modelling of stainless steel SHS and RHS beam-column structural members, was adopted throughout the present numerical simulations. An element size equal to the cross-section thickness was used in the flat parts of the modelled cross-sections, while a finer mesh of four elements was employed to discretise the curved corner regions. Since ABAQUS [38] requires the material properties to be inputted in the form of true stress and log plastic strain, the measured engineering stress-strain curves from tensile coupon tests, represented by the compound two-stage Ramberg-Osgood model [39-43], were converted into true stress-strain curves, according to Eq, (11) and Eq, (12), where $\sigma_{\text {true }}$ is the true tress, $\varepsilon_{l n}^{p l}$ is the log plastic strain, $\sigma_{n o m}$ is the engineering stress and $\varepsilon_{\text {nom }}$ is the engineering strain. The adopted material properties for the present numerical simulations were taken from previous tests on stainless steel SHS and RHS beam-columns $[15,17,19]$. Table 1 summarises the employed material properties for each stainless steel grade, where $E$ is the Young's modulus, $\sigma_{0.2}$ is the $0.2 \%$ proof stress, $\sigma_{1.0}$ is the $1.0 \%$ proof stress, $\sigma_{u}$ is the ultimate tensile strength, and $n, n_{0.2,1.0}^{\prime}$ and $n_{0.2, u}^{\prime}$ are the strain hardening exponents used in the two-stage Ramberg-Osgood (R-O) material model [39-43].

$$
\begin{aligned}
& \sigma_{\text {true }}=\sigma_{\text {nom }}\left(1+\varepsilon_{\text {nom }}\right) \\
& \varepsilon_{\text {ln }}^{p l}=\ln \left(1+\varepsilon_{\text {nom }}\right)-\frac{\sigma_{\text {true }}}{E}
\end{aligned}
$$


Cold-formed stainless steel structural members are generally produced by cold-rolling flat metal sheets into circular tubes, welding them closed and then subsequently deforming them into the required profiles by means of dies. The cold-forming process induces plastic deformations, which result in the development of strength enhancements and throughthickness bending residual stresses in the structural sections, while the welding process introduces membrane residual stresses. In the present study, residual stresses were not explicitly incorporated into the beam-column FE models, due to the inherent presence of the more dominant through-thickness residual stresses in the measured material properties $[1,44,45]$ and the negligible influence of the membrane residual stresses on cold-formed stainless steel tubular profiles $[1,44,45]$. With regards to strength enhancements, the different levels of strength enhancement arising in the flat and corner regions of cold-rolled hollow sections was reflected by utilising the material stress-strain properties obtained from coupons extracted from these respective regions of tested cross-sections. In addition, it has been both experimentally [46] and numerically [47] verified that the high corner strength enhancements are not only restricted to the curved portions of the sections, but also extend into the adjacent flat parts beyond the corners by a distance approximately equal to two times the cross-section thickness. This finding has been adopted in the present numerical study by assigning corner material properties to both of the aforementioned regions, while the remainder of the FE models were assigned the flat material properties.

Symmetry was exploited by modelling only half the cross-section and member length of beam-columns and then applying suitable symmetry boundary conditions, which enabled significant savings in computational time. The end section boundary conditions were applied by coupling all the nodes of the end section to an eccentric reference point, allowing only longitudinal translation and rotation about the axis of buckling. An axial load was applied to 
the beam-column models through the eccentric reference point, resulting in the application of both axial compressive load and bending moment to the beam-columns.

The initial global geometric imperfection distribution along the member length was assumed to be sinusoidal, with the maximum imperfection amplitude equal to $L / 1000$ at mid-height, in accordance with previous numerical studies of stainless steel and carbon steel SHS and RHS beam-columns [19,34,36,37]. Since global member failure of beam-columns with nonslender sections was the focus of the present study, initial local geometric imperfections were considered to have negligible influence on the structural behaviour, and were thus not included in the FE models. Upon incorporation of the initial global geometric imperfections into the numerical models, geometrically and materially nonlinear analyses were conducted, using the modified Riks method [38], to determine the failure loads of the members, which were then employed to calculate the interaction factors according to Eq. (10).

\section{Derivation of interaction factors}

In this section, the numerically derived interaction factors are presented and discussed, before being transformed into simplified formulae. For each stainless steel grade, four sets of curves corresponding to different cross-section slendernesses $\bar{\lambda}_{p}$, defining the relationship between the interaction factor $k_{c s m}$ and member slenderness $\bar{\lambda}$ for varying axial compressive load levels $n=N_{E d} / N_{b, R d}$, were derived. Eight compressive load levels were considered ranging from 0.2 to 0.8 in increments of 0.1 . Table 2 reports the cross-section slendernesses of the two modelled sections in bending about both the major and minor axes, together with the geometric dimensions, where $B$ and $H$ are the section width and depth, respectively, $t$ is the thickness and $r_{i}$ is the internal corner radius. 
For each stainless steel grade, it was generally found that the derived four sets of $k_{c s m}$ data points corresponding to different cross-section slendernesses show a relatively low level of scatter. Typical derived $k_{c s m}$ factors for $n=0.3$ are illustrated in Figs 3(a)-3(c) for austenitic, duplex and ferritic stainless steels, respectively. The rather low level of scatter results mainly from the use of the CSM bending moment capacities $M_{c s m, R d}$ as the bending reference value in the calculation of $k_{c s m}$. As highlighted in Section 3, the continuous strength method (CSM) leads to not only accurate but also consistent bending moment capacity predictions over its application range of cross-section slenderness $\bar{\lambda}_{p}$ less than 0.68 . Thus, the calculated interaction factors based on $M_{c s m, R d}$ contain a much lower level of compensation for erroneous end points and scatter, compared to those based on $M_{p l, R d}$ or $M_{e l, R d}$ in previous studies [34].

The design formulae for $k_{c s m}$ were developed based on the upper set of the FE derived interaction factors (represented for clarity as curves passing through the data points), as shown in Figs 4(a)-4(c) for austenitic, duplex and ferritic stainless steels, respectively. The relationships between the interaction factors and member slenderness generally exhibit a steeper slope in the low slenderness range but a relatively steady slope in the high slenderness range. Thus, the design formulae for $k_{c s m}$ is assumed to be of the traditional bi-linear form, as used for carbon steel beam-column interaction factors [36,37] and given by Eq. (13), where $D_{1}$ and $D_{2}$ are the coefficients, which define the linear relationship between $k_{c s m}$ and $\bar{\lambda}$ in the low member slenderness range, while $D_{3}$ is a limit value, beyond which the interaction factor $k_{c s m}$ remains constant (i.e. there is a zero slope to the proposed $k_{c s m}$ curve for $\bar{\lambda} \geq D_{3}$ ).

$k_{c s m}=1+D_{1}\left(\bar{\lambda}-D_{2}\right) n \leq 1+D_{1}\left(D_{3}-D_{2}\right) n$ 
The values of $D_{1}$ and $D_{2}$ for each axial compressive load level (e.g. $n=0.3$ ) were determined following a regression fit of Eq. (13) to the corresponding numerically derived results over the member slenderness range from 0.2 to 1.2 , while the final $D_{1}$ and $D_{2}$ coefficients were taken as the average calculated values for all the considered load levels (i.e. $0.2 \leq n \leq 0.8$ ). Then, the limit value of $D_{3}$ was determined based on the fit of Eq. (13) to the FE derived results corresponding to low axial compressive load levels (i.e. $n \leq 0.4$ ). Table 3 reports the values of $D_{1}, D_{2}$ and $D_{3}$ for each stainless steel grade, while the comparisons between the FE derived and proposed curves of the interaction factors are shown in Figs 5(a)-5(c). The comparisons indicate that there are relatively large differences between the proposed and FE derived $k_{c s m}$ curves for high axial compressive load levels in the high member slenderness range. However, these deviations only have a minor effect on the beam-column design capacity, since the member resistance is dominated by column buckling for beam-columns of high slenderness at high axial load levels, while the bending term $k_{c s m} M_{c s m, R d}$ has rather little influence; this observation was also made by Greiner and Kettler [34] and Greiner and Linder [36].

Figs 6(a)-6(c) depict the proposed beam-column design interaction curves corresponding to a range of member slendernesses for austenitic, duplex and ferritic stainless steels, respectively, indicating an increasingly concave trend as the member slenderness increases, which is consistent with the increasingly significant second order effects as member slenderness grows. The proposed beam-column design formulae for each stainless steel grade reduce to the same cross-section design expression when member slenderness tends to zero, as shown in Eq. (14), which offers a good representation of the CSM interaction curve (Eq. (15)) for cross-section resistance under combined loading, previously proposed by the authors $[18,26]$, and is more accurate than the EN 1993-1-4 cross-section interaction curve (Eq. (16)); this is also shown in 
Fig. 7, where $M_{R, R d}$ and $M_{R, c s m, R d}$ are respectively the reduced plastic moment capacity and reduced CSM bending resistance due to the existence of the axial force $N_{E d}, a_{w}$ is the ratio of the web area to gross cross-section area, $N_{p l, R d}=A \sigma_{0.2} / \gamma_{M 0}$ is the yield load, and $N_{c s m, R d}$ is the CSM compression resistance.

$$
\begin{aligned}
& \frac{N_{E d}}{N_{p l, R d}}+\left(1-0.6 \frac{N_{E d}}{N_{p l, R d}}\right) \frac{M_{E d}}{M_{c s m, R d}} \leq 1 \\
& M_{E d} \leq M_{R, c s m, R d}=M_{c s m, R d} \frac{\left(1-N_{E d} / N_{c s m, R d}\right)}{\left(1-0.5 a_{w}\right)} \leq M_{c s m, R d} \\
& M_{E d} \leq M_{R, R d}=M_{p l, R d} \frac{\left(1-N_{E d} / N_{p l, R d}\right)}{\left(1-0.5 a_{w}\right)} \leq M_{p l, R d}
\end{aligned}
$$

\section{Comparisons with test and FE results}

The accuracy of the proposed design approaches was assessed through comparisons against a large number of test and FE results. The experimental data were collected from the literature and included tests on austenitic [9], duplex [15,16] and ferritic [19] stainless steel SHS and RHS beam-columns, while the numerical data were generated through parametric studies. In the parametric studies, the outer width of the modelled cross-sections was set equal to 100 $\mathrm{mm}$ while the outer depths ranged from $100 \mathrm{~mm}$ to $200 \mathrm{~mm}$, leading to cross-section aspect ratios between 1.0 and 2.0. The internal corner radii were set equal to the cross-section thickness, which varied from $3.5 \mathrm{~mm}$ to $11 \mathrm{~mm}$, resulting in a range of cross-section slenderness $\bar{\lambda}_{p}$ between 0.20 and 0.62 . The lengths of the beam-columns models were varied to cover a wide spectrum of member slenderness $\bar{\lambda}$ between 0.2 and 3.0 , and the initial loading eccentricities ranged from $1 \mathrm{~mm}$ to $1250 \mathrm{~mm}$, enabling a broad range of loading combinations (i.e. ratios of axial load to bending moment) to be considered. In total, 3090 
parametric study results were generated, including 1190 for austenitic stainless steel, 900 for duplex stainless steel and 1000 for ferritic stainless steel.

The accuracy of the proposed design approach, as well as that of existing design methods was evaluated through comparisons of the test and FE beam-column strengths with the unfactored (i.e. all partial factors set to unity) predicted strengths, based on the measured or modelled geometries and weighted average (by area) material properties to allow for the higher strengths in the corners. The comparisons are presented in terms of the failure load ratio, $N_{u} / N_{u, \text { pred }}[18,19,48-50]$, of which the definition is illustrated in Fig. 8, where $N_{u}$ is the test or FE failure load corresponding to the distance on the $\mathrm{N}-\mathrm{M}$ interaction curve from the origin to the test data point, and $N_{u, p r e d}$ is the predicted axial load corresponding to the distance from the origin to the intersection with the design interaction curve, assuming proportional loading. Tables 4(a)-4(c) report the ratios of test and FE beam-column failure loads to predicted failure loads for the austenitic, duplex and ferritic stainless steel beam-columns, respectively. Note that ratios greater than unity indicate that the test (or FE) data points lie on the safe side (i.e. outside) of the design interaction curve.

The experimental and numerical results are compared with the strength predictions from each method in Figs 9-11 for the austenitic, duplex and ferritic stainless steel grades, respectively, where the test (or FE) to predicted failure load ratio $N_{u} / N_{u \text {,pred }}$ is plotted against the angle parameter $\theta$, which is defined by Eq. (17) and illustrated in Fig. 12, where $N_{R}$ and $M_{R}$ are the predicted member strengths under pure compression and pure bending, respectively (i.e. column buckling strength and cross-section bending moment capacity). Note that $\theta=0^{\circ}$ corresponds to pure bending while $\theta=90^{\circ}$ represents pure compression.

$\theta=\tan ^{-1}\left[\left(N_{E d} / N_{R}\right) /\left(M_{E d} / M_{R}\right)\right]$ 
For each stainless steel grade, comparisons between the EN 1993-1-4 [31] and SEI/ASCE-8 [32] design methods and the test and FE beam-column strengths generally reveal scattered results with a transition from slightly unsafe predictions of column buckling loads to unduly conservative bending moment resistances, as the applied loading varies from pure compression to pure bending (i.e. as $\theta$ moves from $90^{\circ}$ to $0^{\circ}$ ). The Australian/New Zealand standard AS/NZS 4673 [33] results in reduced scatter in the strength predictions, compared to the European code and American specification, but with some predictions still on the unsafe side. The proposed approach yields the highest degree of accuracy and consistency in the prediction of beam-column strengths for all loading combinations (i.e. $0^{\circ} \ldots \ldots \ldots$ ). As reported in Tables 4(a)-4(c), the mean ratios of the test and FE failure loads to predicted failure loads determined from the proposed beam-column design method $N_{u} / N_{u, p}$ are equal to $1.07,1.06$ and 1.06 with coefficients of the variation $(\mathrm{COV})$ of $0.04,0.03$ and 0.02 for the austenitic, duplex and ferritic stainless steel beam-columns, respectively, indicating that the proposed approach results in precise and consistent predictions, and a scatter of generally about one half to one third that of existing codified methods. Comparisons were also made based on test data only, as shown in Figs 13(a)-13(c) for the austenitic, duplex and ferritic stainless steel beam-columns, respectively, and the mean ratios of test to predicted capacities $N_{u, \text { test }} / N_{u, \text { pred }}$ are reported in Tables 5(a)-5(c).

Use of the proposed interaction factors, but with EC3 bending moment capacities and revised column buckling strengths [29] as the end points of the interaction curve, was also assessed. The mean test and FE to predicted failure load ratios $N_{u} / N_{u, E C 3, \text { rev. }}$, as reported in Table 4(a)4(c), are $1.15,1.16$ and 1.09 for the austenitic, duplex and ferritic stainless steel beamcolumns, respectively, which are lower than those resulting from the current European code 
and thus indicate improved accuracy, and the corresponding COVs are 0.05, 0.04 and 0.04, showing that the scatter is generally half that of EN 1993-1-4, as also observed in Table 5(a)5(c). In addition, this revised EC3 approach yields safe beam-column strength predictions for all the loading combinations, as shown in Figs 14(a)-14(c), where the ratio of test (or FE) failure load to predicted failure load $N_{u} / N_{u, E C 3, \text { rev. }}$ is plotted against the angle parameter $\theta$.

\section{Reliability analysis}

In this section, the reliability of the proposed beam-column design approach and the revised EC3 treatment is assessed through statistical analyses, according to the provisions of EN 1990 [51]. A summary of the key calculated statistical parameters for the two proposals is reported in Table 6 , where $k_{d, n}$ is the design (ultimate limit state) fractile factor, $b$ is the average ratio of test (or FE) to design model resistance based on a least squares fit to all data, $V_{\delta}$ is the $\mathrm{COV}$ of the tests and $\mathrm{FE}$ simulations relative to the resistance model, $V_{r}$ is the combined COV incorporating both model and basic variable uncertainties, and $\gamma_{M 1}$ is the partial safety factor for member resistance. In the analyses, the over-strength ratios for material yield strength were taken as $1.3,1.1$ and 1.2 , with COVs of equal to $0.060,0.030$ and 0.045 , for the austenitic, duplex and ferritic stainless steels, respectively, while the COV of geometric properties was taken as 0.050 for all the stainless steel grades, as recommended by Afshan et al. [52]. As can be seen from Tables 6(a) and 6(b), the partial factors for both the proposed beam-column design method and the revised EC3 treatment are less than the currently adopted value of 1.1 in EN 1993-1-4 [31], and thus demonstrate that the beamcolumn proposals satisfy the reliability requirements of EN 1990 [51]. 


\section{Conclusions}

Current design provisions for stainless steel beam-columns, as set out in the European code EN 1993-1-4 [31], American specification SEI/ASCE-8 [32] and Australian/New Zealand standard AS/NZS 4673 [33] have been shown in previous studies to have some shortcomings. In particular, the design interaction curves were generally developed based on inaccurate end points (i.e. conservative elastic or plastic bending moment capacities in bending and often over-predicted column buckling strengths in compression). This, in turn, led to the derivation of interaction factors that partially accounted for interaction effects and partially compensated for inaccurate end points. To overcome these shortcomings, new beam-column interaction factors have been developed in this study, based on more accurate end points (i.e. the CSM bending moment capacities [24] and revised column buckling strengths [29]). The derived interaction factors apply to all the non-slender SHS and RHS, according to EN 1993-1-4 slenderness limits [31]. The accuracy of the proposed beam-column design rules has been assessed through comparisons against over 3000 test and FE data. The comparisons revealed that the proposals provide more accurate and consistent predictions of stainless steel beamcolumn strengths than current codified design approaches. Use of the proposed interaction factors but with the EC3 bending moment capacities and revised column buckling strengths [29] as the end points was also considered, and found to offer more accurate and less scattered strength predictions than the current European code. The reliability of the proposals was demonstrated by means of statistical analyses according to the provisions of EN 1990 [51]. It is therefore recommended that the proposed approach for stainless steel SHS and RHS beam-columns be considered for incorporation into future revisions of stainless steel structural design standards. 


\section{Acknowledgements}

The authors would like to thank the Joint PhD Scholarship from Imperial College London and the University of Hong Kong for its financial support.

\section{References}

[1] Rasmussen KJR, Hancock GJ. Design of cold-formed stainless steel tubular members. I: Columns. Journal of Structural Engineering (ASCE), 1993;119(8):2349-67.

[2] Kuwamura H. Local buckling of thin-walled stainless steel members. Steel Structures, 2003;3:191-201

[3] Gardner L, Nethercot DA. Experiments on stainless steel hollow sections - Part 1: Material and cross-sectional behaviour. Journal of Constructional Steel Research, 2004;60(9):1291-318.

[4] Young B, Lui WM. Behavior of cold-formed high strength stainless steel sections. Journal of Structural Engineering (ASCE), 2005;131(11):1738-45.

[5] Gardner L, Talja A, Baddoo N. Structural design of high-strength austenitic stainless steel. Thin-Walled Structures, 2006;44(5):517-28.

[6] Theofanous M, Gardner L. Testing and numerical modelling of lean duplex stainless steel hollow section columns. Engineering Structures, 2009;31(12):3047-58. 
[7] Afshan S, Gardner L. Experimental study of cold-formed ferritic stainless steel hollow sections. Journal of Structural Engineering (ASCE), 2013;139(5):717-28.

[8] Bock M, Arrayago I, Real E. Experiments on cold-formed ferritic stainless steel slender sections. Journal of Constructional Steel Research, 2015;109:13-23.

[9] Talja A, Salmi P. Design of stainless steel RHS beams, columns and beam-columns. Technical Research Centre of Finland, Finland; 1995.

[10] Gardner L, Nethercot DA. Experiments on stainless steel hollow sections - Part 2: Member behaviour of columns and beams. Journal of Constructional Steel Research, 2004;60(9):1319-32.

[11] Huang Y, Young B. Structural performance of cold-formed lean duplex stainless steel columns. Thin-Walled Structures, 2014;83:59-69.

[12] Rasmussen KJR, Hancock GJ. Design of cold-formed stainless steel tubular members. II: beams. Journal of Structural Engineering (ASCE), 1993;119(8):2368-86.

[13] Theofanous M, Gardner L. Experimental and numerical studies of lean duplex stainless steel beams. Journal of Constructional Steel Research, 2010;66(6):816-25.

[14] Theofanous M, Saliba N, Zhao O, Gardner, L. Ultimate response of stainless steel continuous beams. Thin-Walled Structures, 2014;83:115-27.

[15] Huang Y, Young B. Experimental investigation of cold-formed lean duplex stainless steel beam-columns. Thin-Walled Structures, 2014;76:105-17. 
[16] Lui WM, Ashraf M, Young B. Tests of cold-formed duplex stainless steel SHS beamcolumns. Engineering Structures, 2014;74:111-21.

[17] Zhao O, Rossi B, Gardner L, Young, B. Behaviour of structural stainless steel crosssections under combined loading - Part I: Experimental study. Engineering Structures, $2015 ; 89: 236-46$

[18] Zhao O, Rossi B, Gardner L, Young B. Experimental and numerical studies of ferritic stainless steel tubular cross-sections under combined compression and bending. Journal of Structural Engineering (ASCE), 2016;142(2):04015110.

[19] Zhao O, Gardner L, Young B. Buckling of ferritic stainless steel members under combined axial compression and bending. Journal of Constructional Steel Research, $2016 ; 117: 35-48$.

[20] Arrayago I, Real E. Experimental study on ferritic stainless steel RHS and SHS crosssectional resistance under combined loading. Structures, 2015;4:69-79.

[21] Ashraf, M, Gardner, L, Nethercot, DA. Compression strength of stainless steel crosssections. Journal of Constructional Steel Research, 2006;62(1-2),105-15.

[22] Ashraf M, Gardner L, Nethercot DA. Structural stainless steel design: resistance based on deformation capacity. Journal of Structural Engineering (ASCE), 2008;134(3):402-11.

[23] Gardner L. The Continuous Strength Method. Proceedings of the Institution of Civil Engineers - Structures and Buildings, 2008;161(3):127-33. 
[24] Afshan S, Gardner L. The continuous strength method for structural stainless steel design. Thin-Walled Structures, 2013;68(4):42-49.

[25] Liew A, Gardner L. Ultimate capacity of structural steel cross-sections under compression, bending and combined loading. Structures, 2015;1:2-11.

[26] Zhao O, Rossi B, Gardner L, Young B. Behaviour of structural stainless steel crosssections under combined loading - Part II: Numerical modelling and design approach. Engineering Structures, 2015;89:247-59.

[27] Schafer BW. Review: the direct strength method of cold-formed steel member design. Journal of Constructional Steel Research, 2008;64(7):766-78.

[28] Becque J, Lecce M, Rasmussen KJR. The direct strength method for stainless steel compression members. Journal of Constructional Steel Research, 2008;64(11):1231-8.

[29] Afshan S, Zhao O, Gardner L. Buckling curves for the design of stainless steel columns. Journal of Constructional Steel Research, submitted.

[30] Trahair NS, Bradford MA, Nethercot DA, Gardner L. The behaviour and design of steel structures to EC3. CRC Press, 2007.

[31] EN 1993-1-4:2006+A1:2015. Eurocode 3: Design of steel structures - Part 1.4: General rules - Supplementary rules for stainless steels, including amendment A1 (2015). Brussels: European Committee for Standardization (CEN); 2015.

[32] SEI/ASCE 8-02. Specification for the design of cold-formed stainless steel structural members. Reston: American Society of Civil Engineers (ASCE); 2002. 
[33] AS/NZS 4673. Cold-formed stainless steel structures. Sydney: AS/NZS 4673:2001; 2001.

[34] Greiner R, Kettler M. Interaction of bending and axial compression of stainless steel members. Journal of Constructional Steel Research, 2008;64(11):1217-24.

[35] Schafer BW, Ádány S. Buckling analysis of cold-formed steel members using CUFSM: conventional and constrained finite strip methods. In: Proceedings of the eighteenth international specialty conference on cold-formed steel structures, Orlando, USA; 2006. p. $39-54$.

[36] Greiner R, Lindner J. Interaction formulae for members subjected to bending and axial compression in EUROCODE 3 - the Method 2 approach. Journal of Constructional Steel Research, 2006;62(8):757-70.

[37] Boissonnade N, Greiner R, Jaspart J-P, Lindner J. Rules for Member Stability in EN 1993-1-1: Background documentation and design guidelines. ECCS European Convention for Constructional Steelwork, 2006.

[38] Hibbitt, Karlsson \& Sorensen, Inc. ABAQUS. ABAQUS/Standard user's manual volumes I-III and ABAQUS CAE manual. Version 6.12. Pawtucket (USA); 2012.

[39] Ramberg W, Osgood WR. Description of stress-strain curves by three parameters. Technical note No 902, Washington DC: National advisory committee for aeronautics; 1943.

[40] Hill HN. Determination of stress-strain relations from offset yield strength values. Technical note No 927, Washington DC: National advisory committee for aeronautics; 1944. 
[41] Mirambell E, Real E. On the calculation of deflections in structural stainless steel beams: An experimental and numerical investigation. Journal of Constructional Steel Research, 2000;54(1):109-33.

[42] Rasmussen KJR. Full-range stress-strain curves for stainless steel alloys. Journal of Constructional Steel Research, 2003;59(1):47-61.

[43] Gardner L, Ashraf M. Structural design for non-linear metallic materials. Engineering Structures, 2006;28(6):926-34.

[44] Cruise RB, Gardner L. Residual stress analysis of structural stainless steel sections. Journal of Constructional Steel Research, 2008;64(3):352-66.

[45] Huang Y, Young B. Material properties of cold-formed lean duplex stainless steel sections. Thin-Walled Structures, 2012;54(7):72-81.

[46] Cruise RB, Gardner L. Strength enhancements induced during cold forming of stainless steel sections. Journal of Constructional Steel Research, 2008;64(11):1310-6.

[47] Gardner L, Nethercot DA. Numerical modeling of stainless steel structural components A consistent approach. Journal of Structural Engineering (ASCE), 2004;130(10):1586-601.

[48] Zhao O, Gardner L, Young B. Testing and numerical modelling of austenitic stainless steel CHS beam-columns. Engineering Structures, 2016;111:263-74.

[49] Zhao O, Gardner L, Young B. Structural performance of stainless steel circular hollow sections under combined axial load and bending - Part 1: Experiments and numerical modelling. Thin-Walled Structures, 2016;101:231-39. 
[50] Zhao O, Gardner L, Young B. Structural performance of stainless steel circular hollow sections under combined axial load and bending - Part 2: Parametric studies and design. Thin-Walled Structures, 2016;101:240-48.

[51] EN 1990. Eurocode - basis of structural design. Brussels: European Committee for Standardization (CEN); 2002.

[52] Afshan S, Francis P, Baddoo NR, Gardner L. Reliability analysis of structural stainless steel design provisions. Journal of Constructional Steel Research, 2015;114:293-304. 


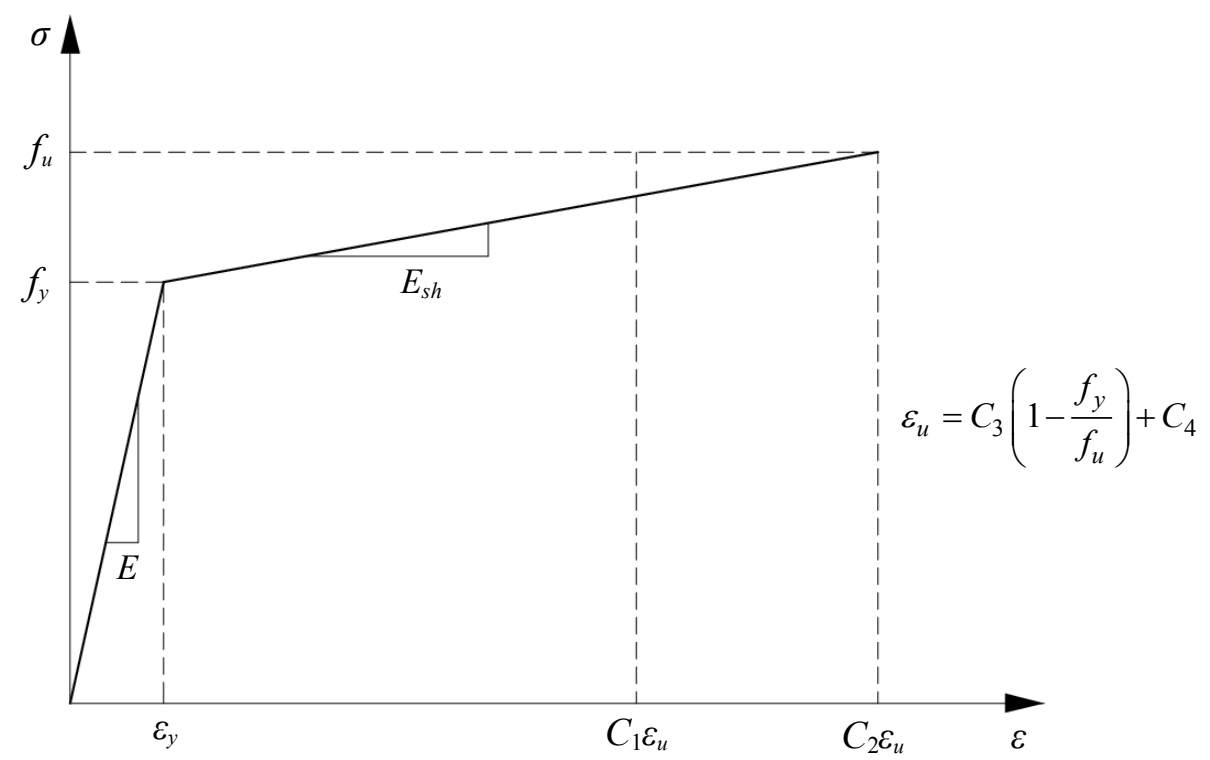

Fig. 1. CSM elastic, linear hardening material model.

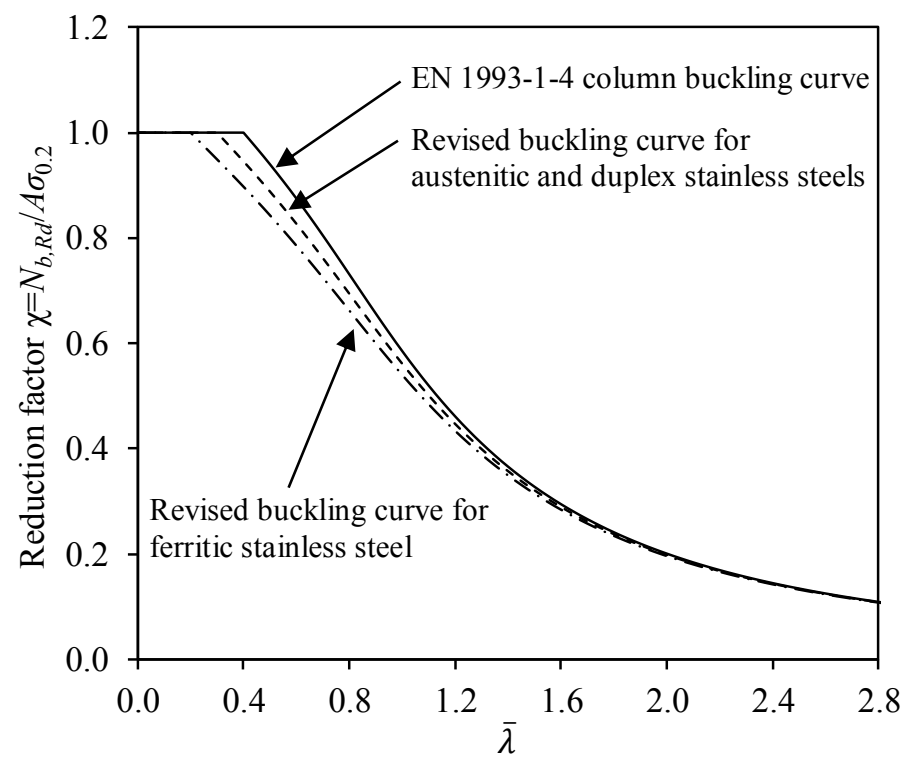

Fig. 2. Comparisons between the EN 1993-1-4 and proposed column buckling curves for cold-formed stainless steel SHS and RHS. 


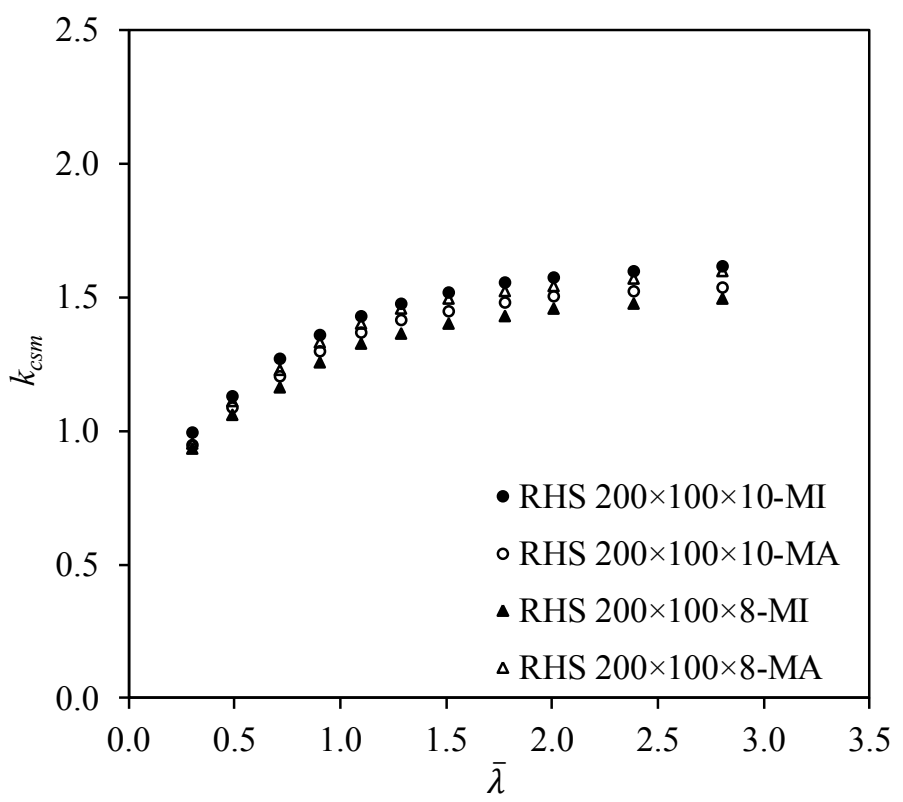

(a) Austenitic stainless steel.

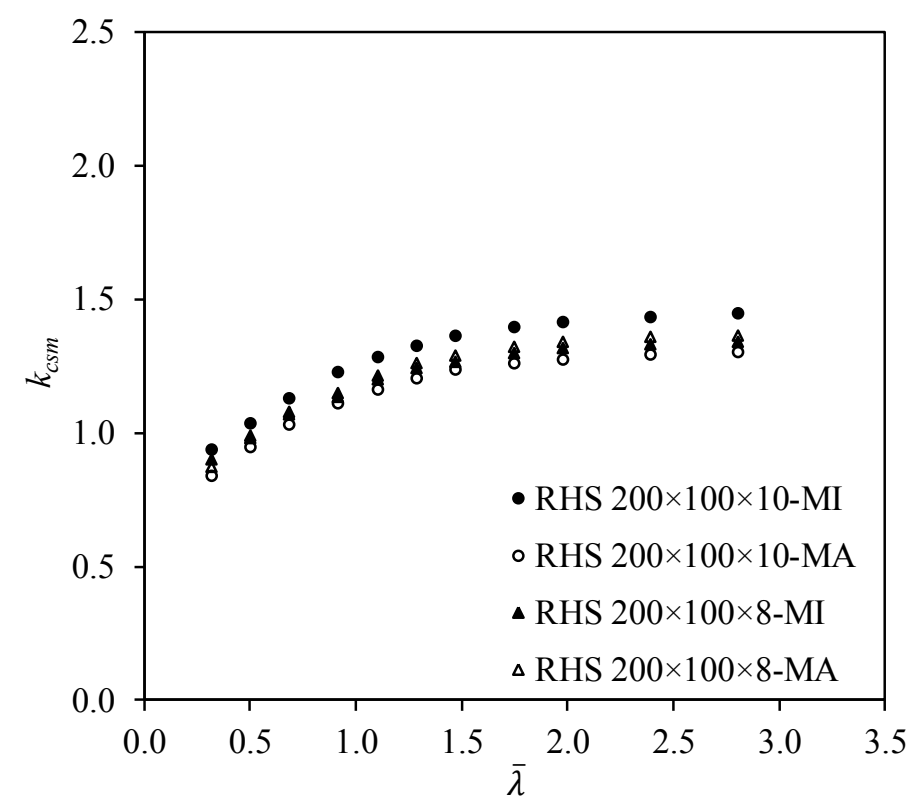

(b) Duplex stainless steel.

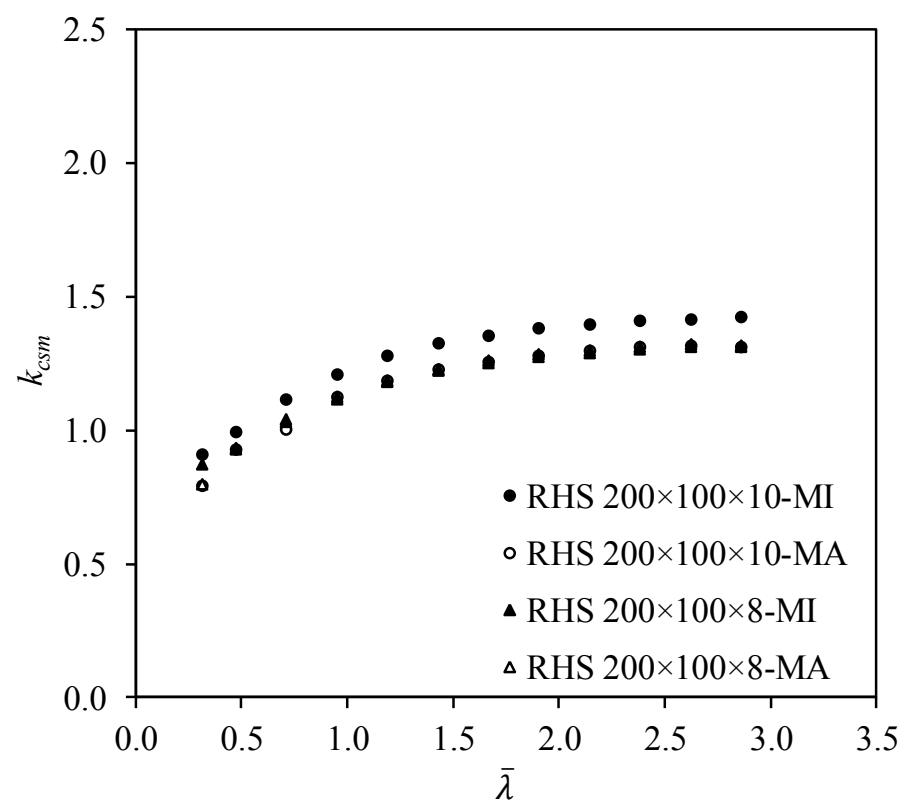

(c) Ferritic stainless steel.

Fig. 3. Typical FE derived $k_{c s m}$ factors corresponding to $n=0.3$. 


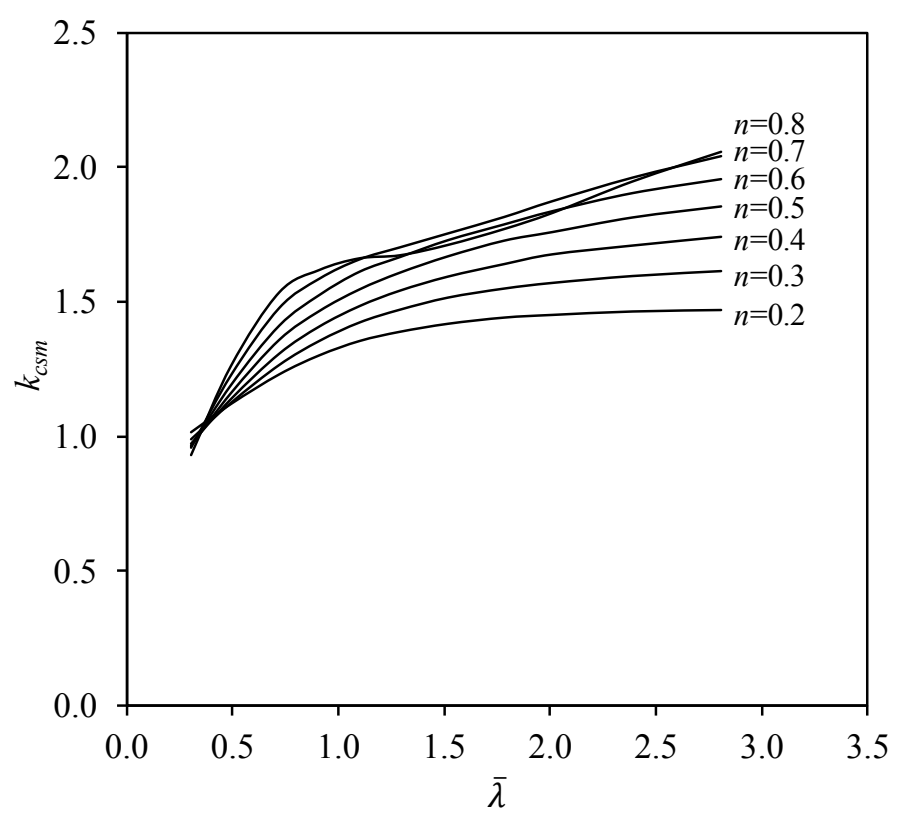

(a) Austenitic stainless steel.

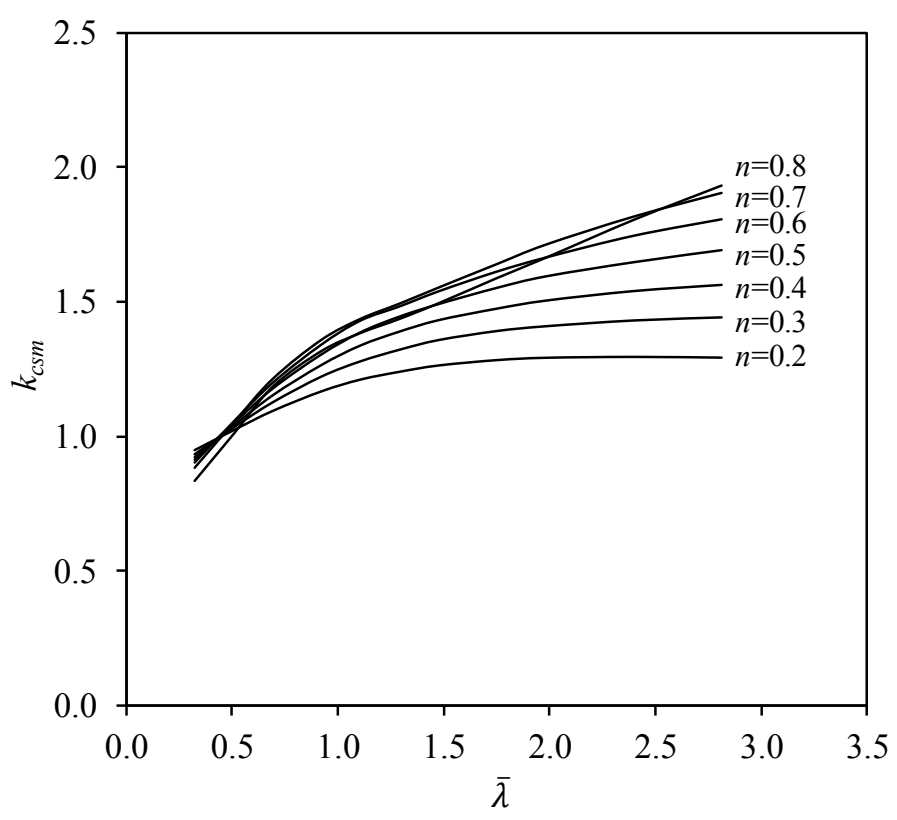

(b) Duplex stainless steel.

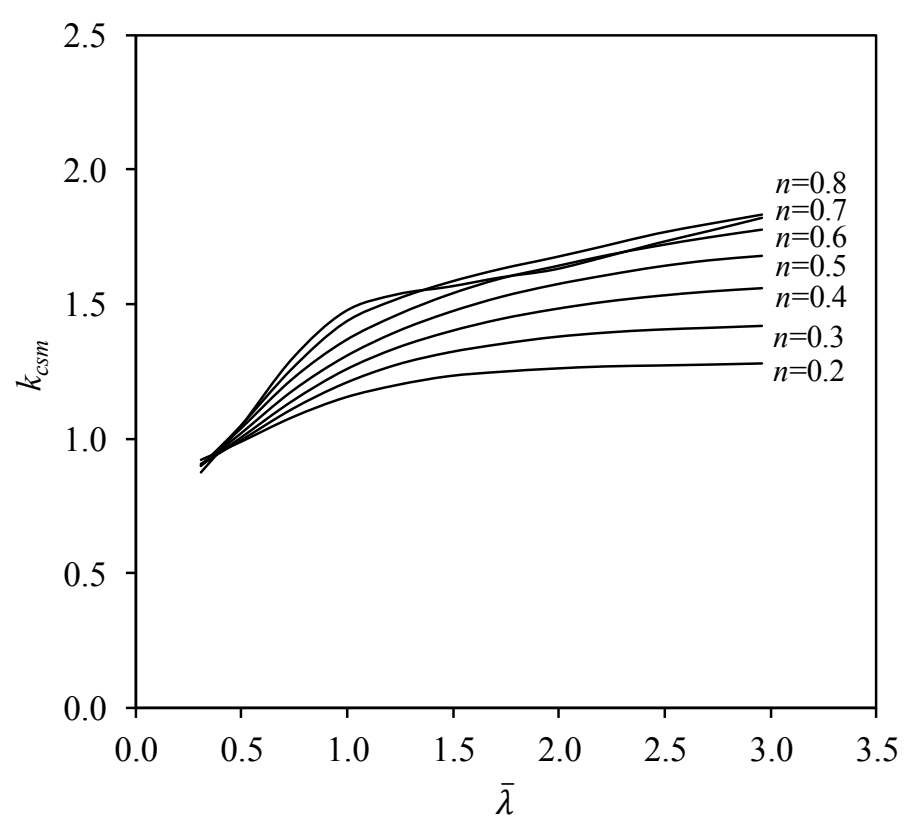

(c) Ferritic stainless steel.

Fig. 4. FE derived curves for interaction factors $k_{c s m}$. 


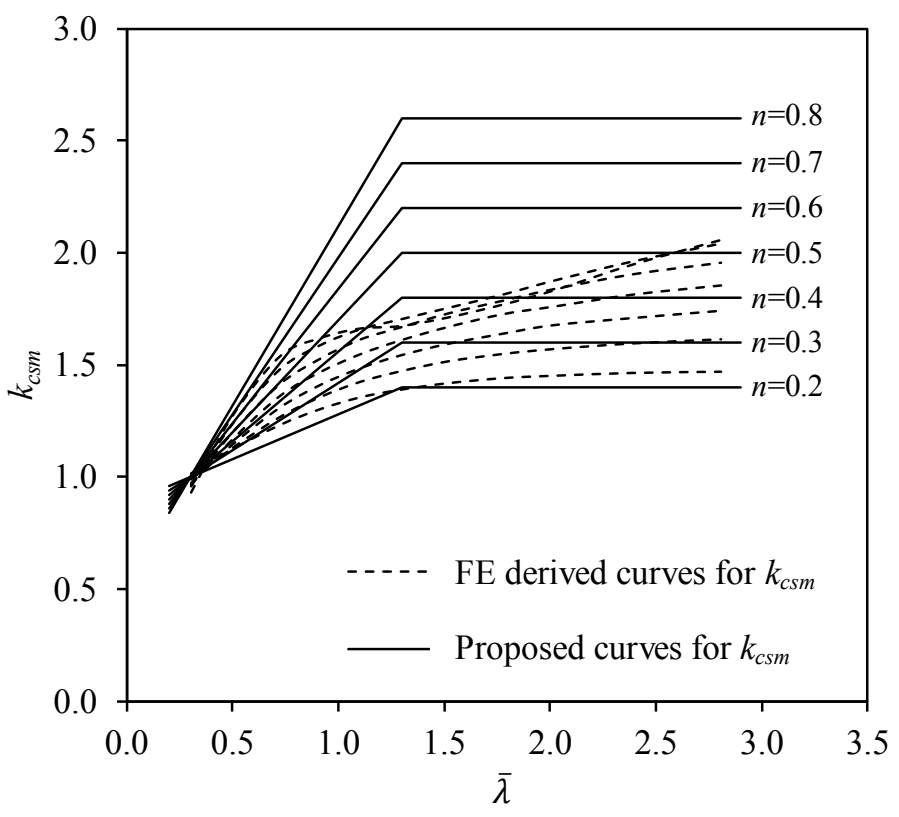

(a) Austenitic stainless steel.

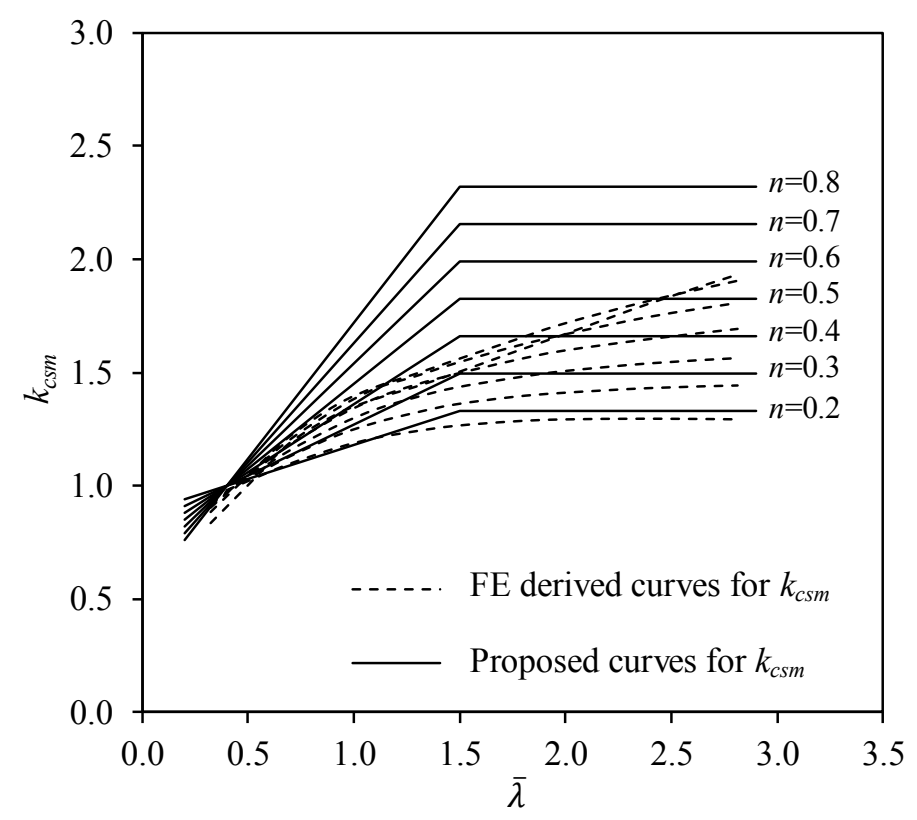

(b) Duplex stainless steel.

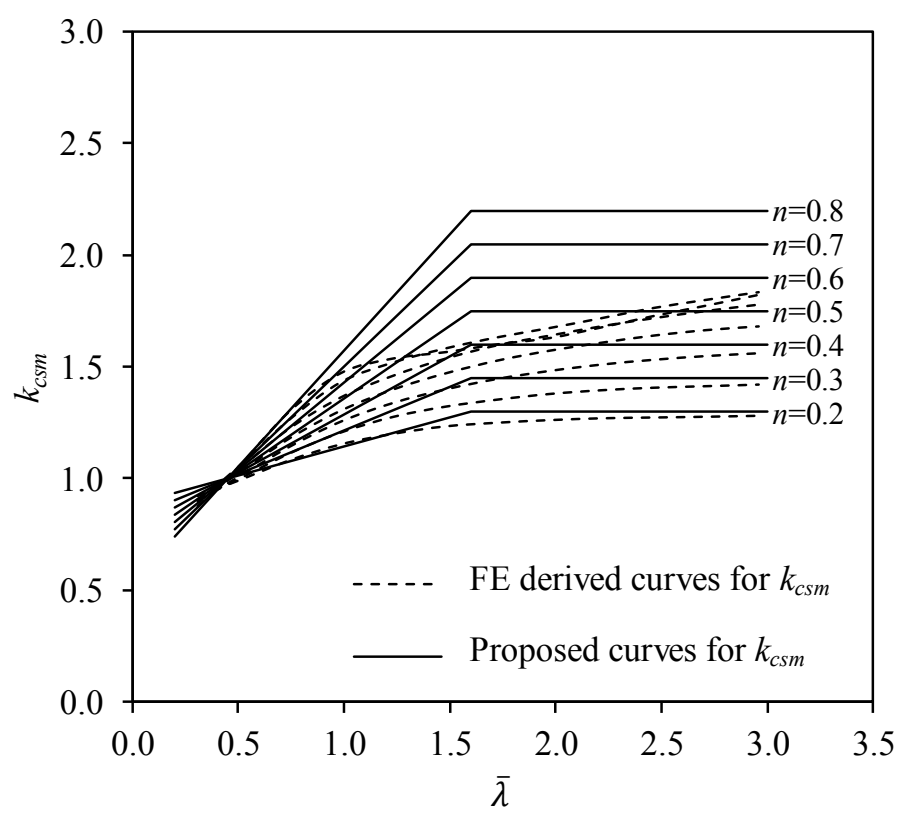

(c) Ferritic stainless steel.

Fig. 5. Comparisons between the proposed and FE derived curves for interaction factors. 


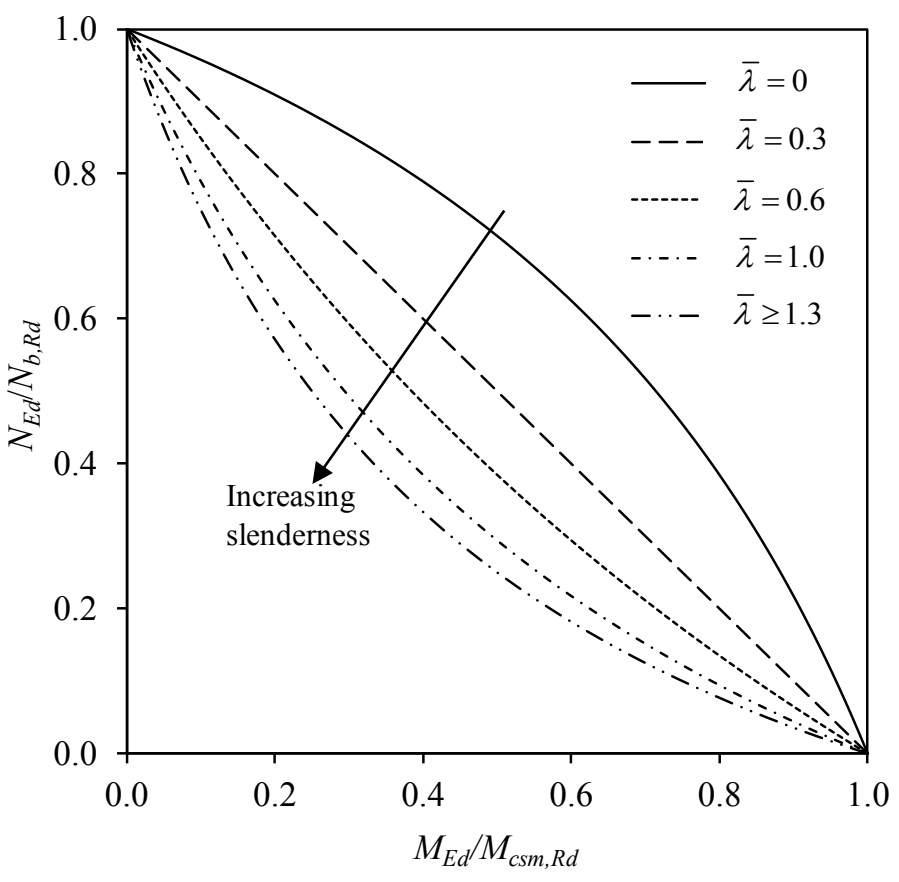

(a) Austenitic stainless steel.

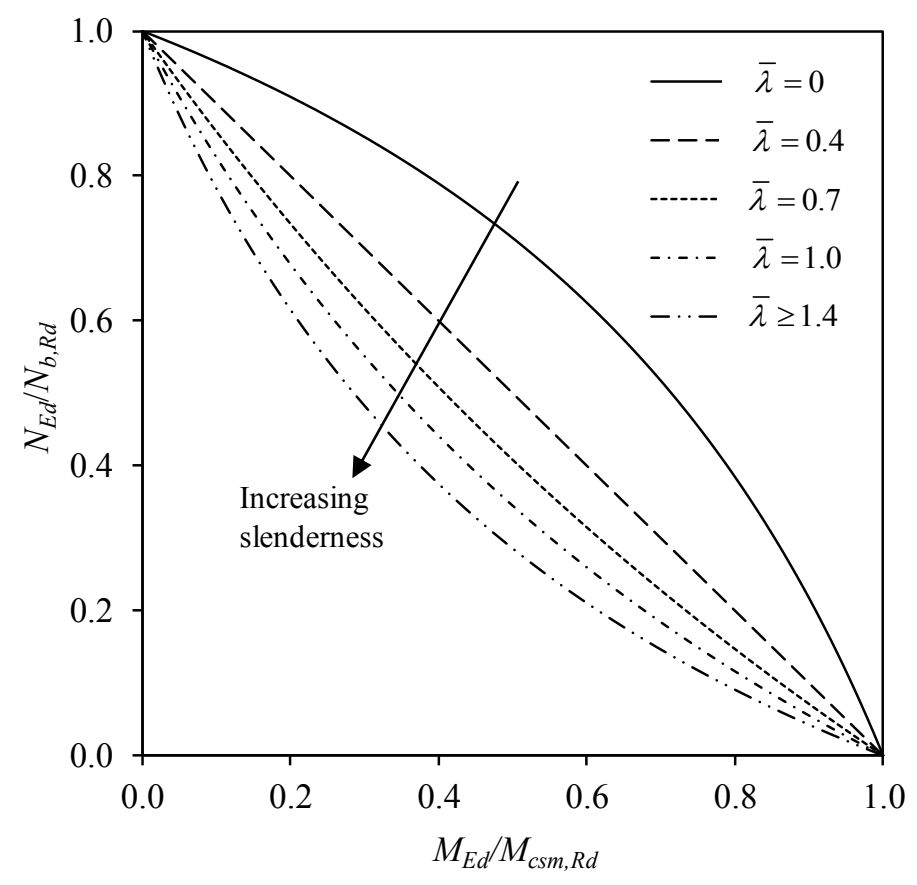

(b) Duplex stainless steel.

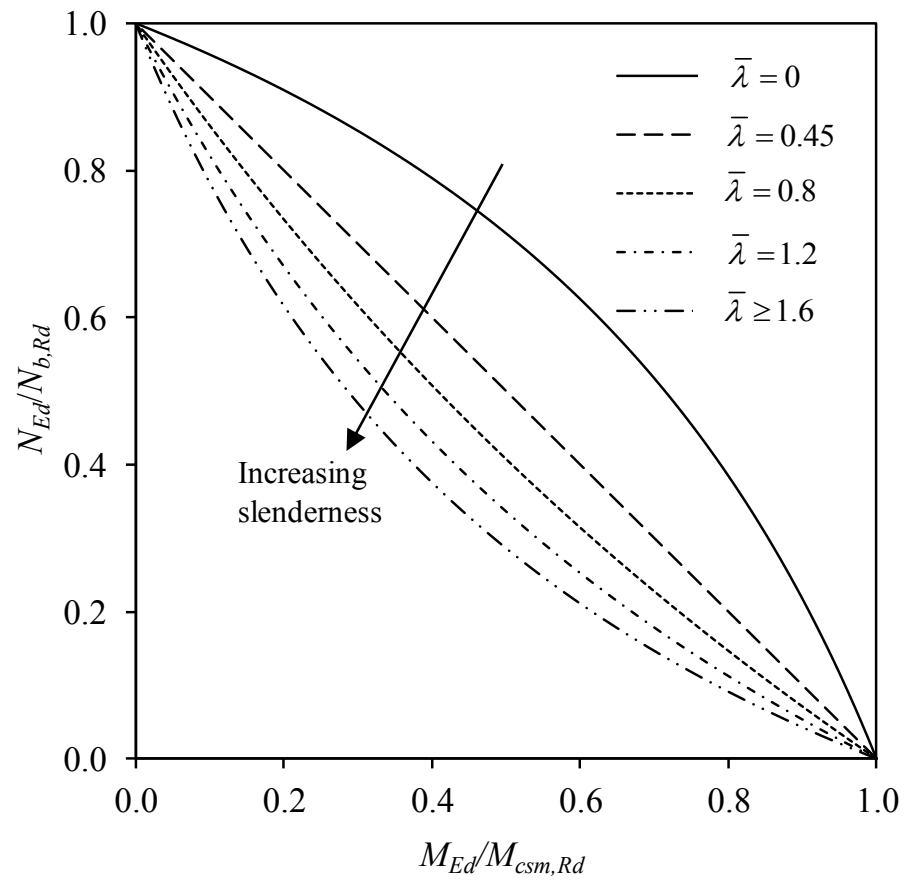

(c) Ferritic stainless steel.

Fig. 6. Proposed beam-column design interaction curves for varying member slendernesses. 


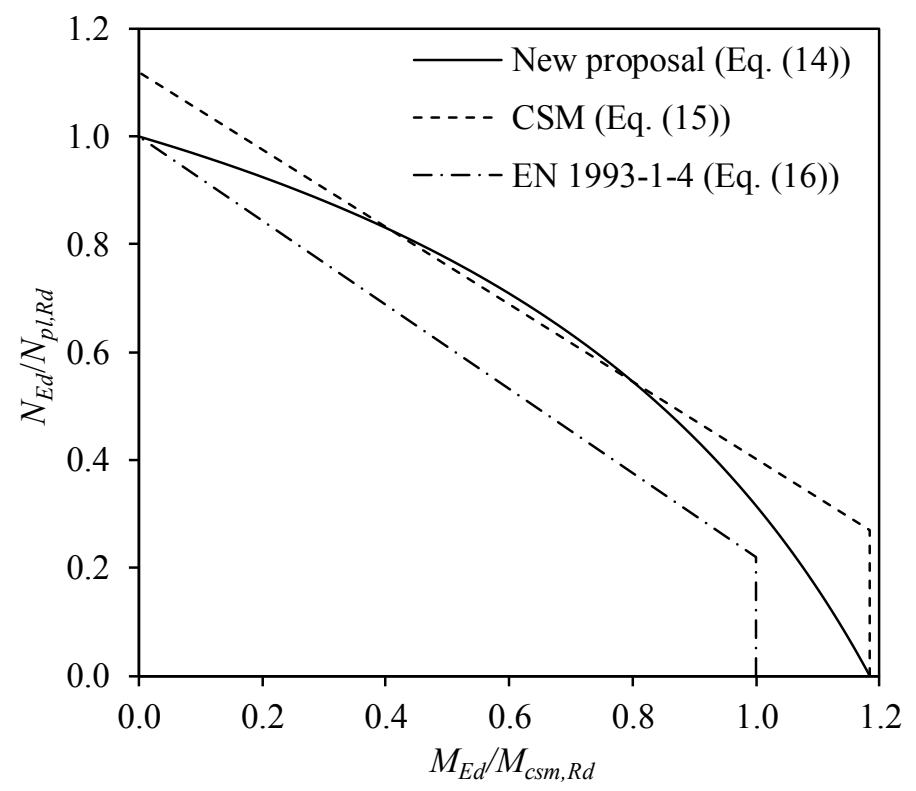

Fig. 7. Cross-section design interaction curves.

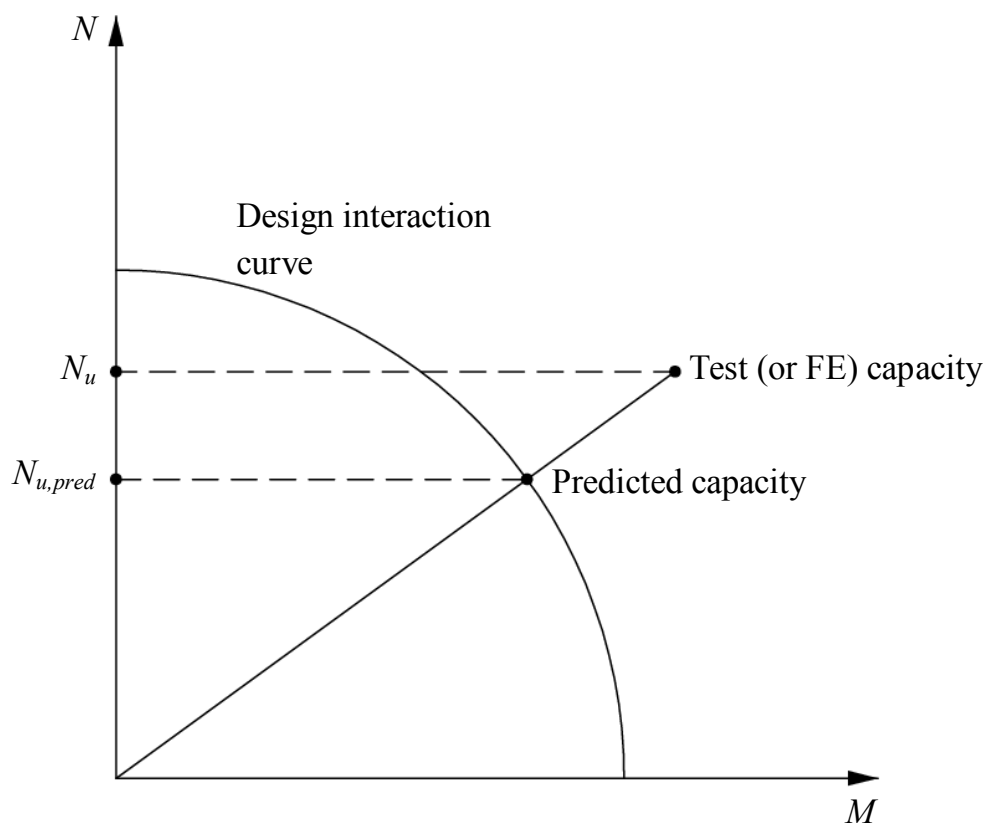

Fig. 8. Definition of $N_{u}$ and $N_{u \text {,pred }}$ on axial load-moment interaction curve. 


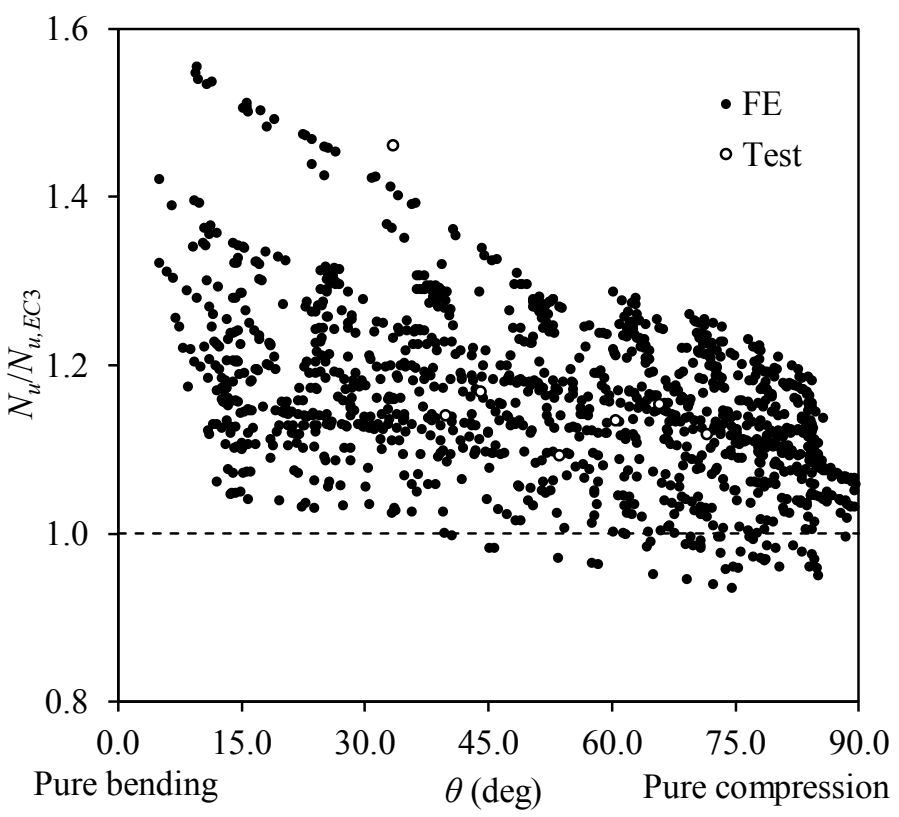

(a) EN 1993-1-4.

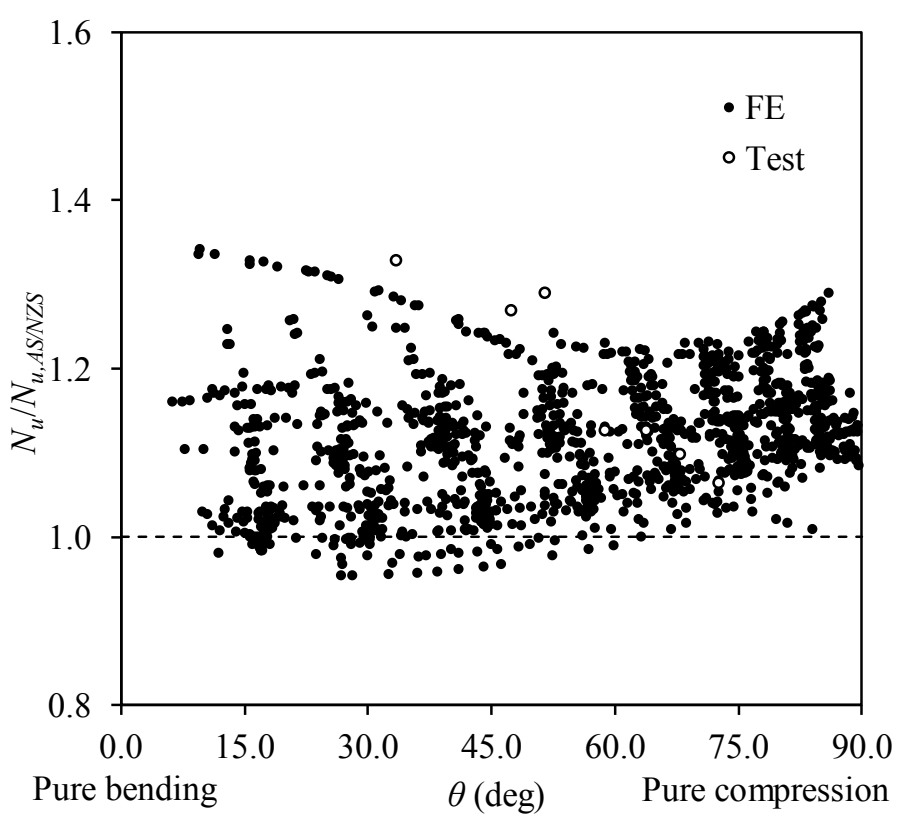

(c) AS/NZS 4673.

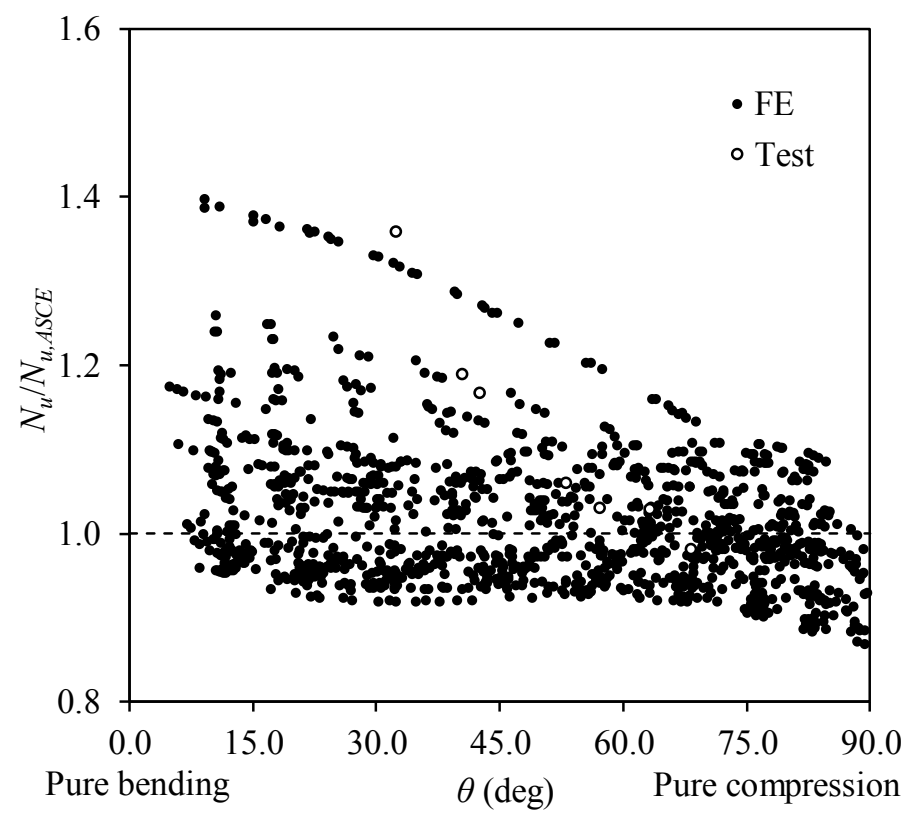

(b) SEI/ASCE-8.

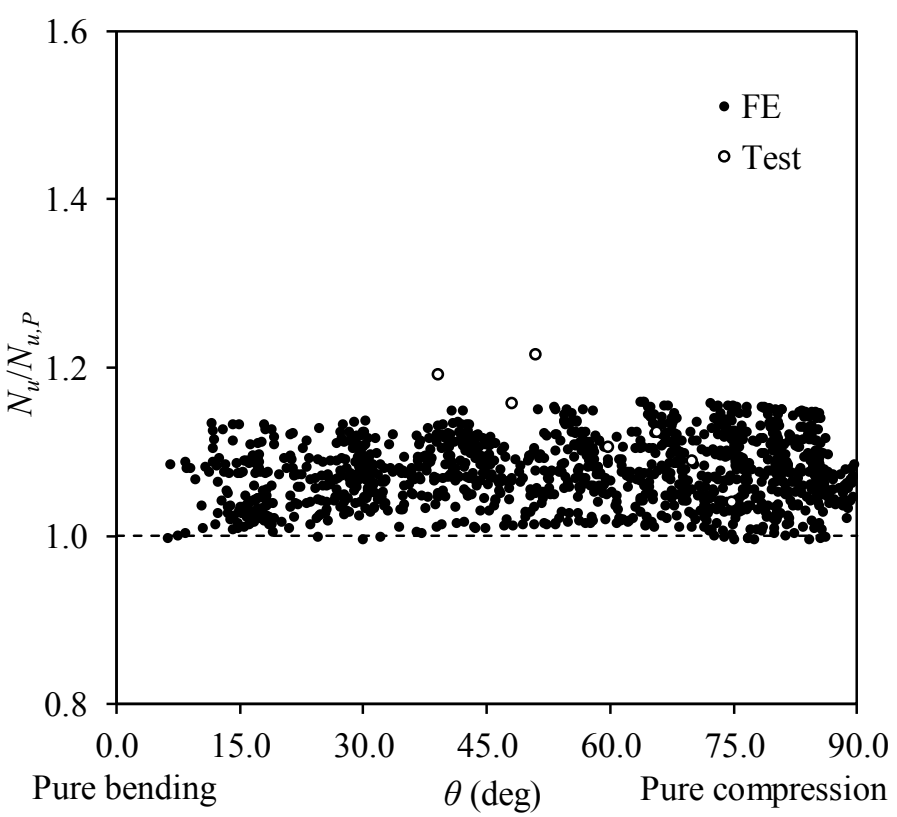

(d) Proposed approach.

Fig. 9. Comparison of austenitic stainless steel beam-column test and FE results with predicted strengths. 


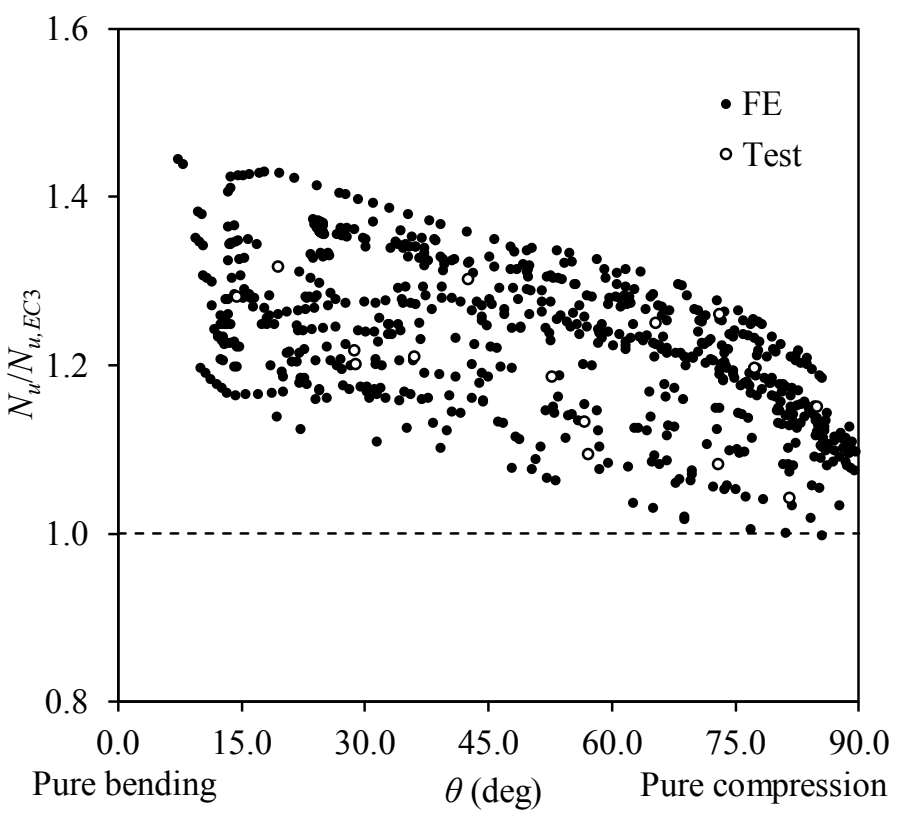

(a) EN 1993-1-4.

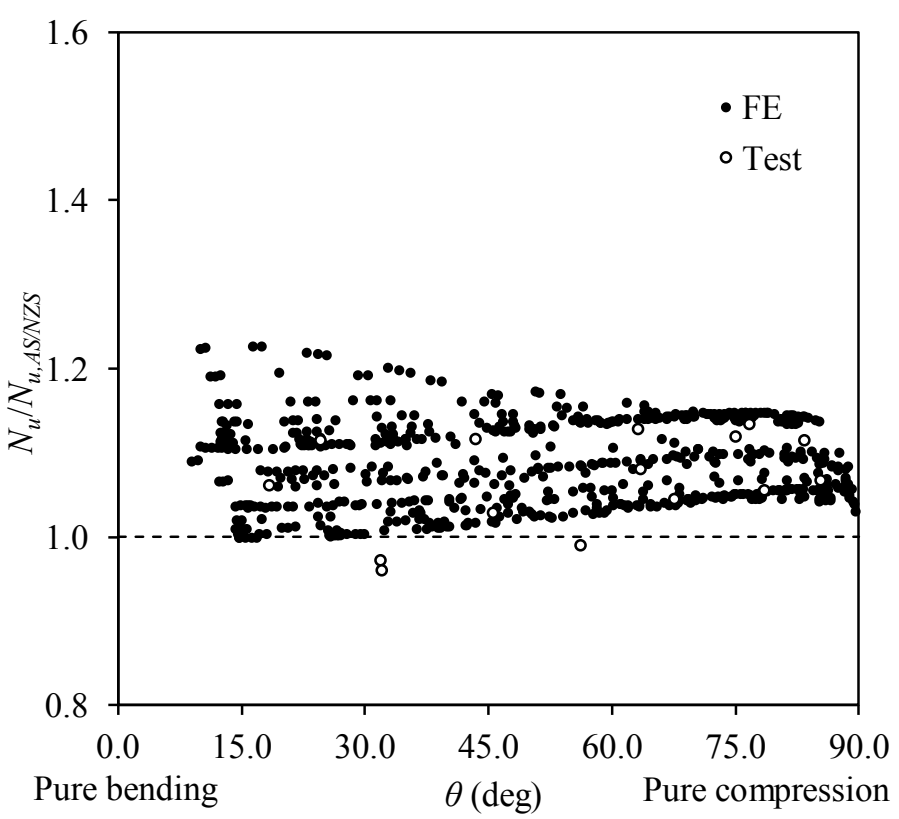

(c) AS/NZS 4673.

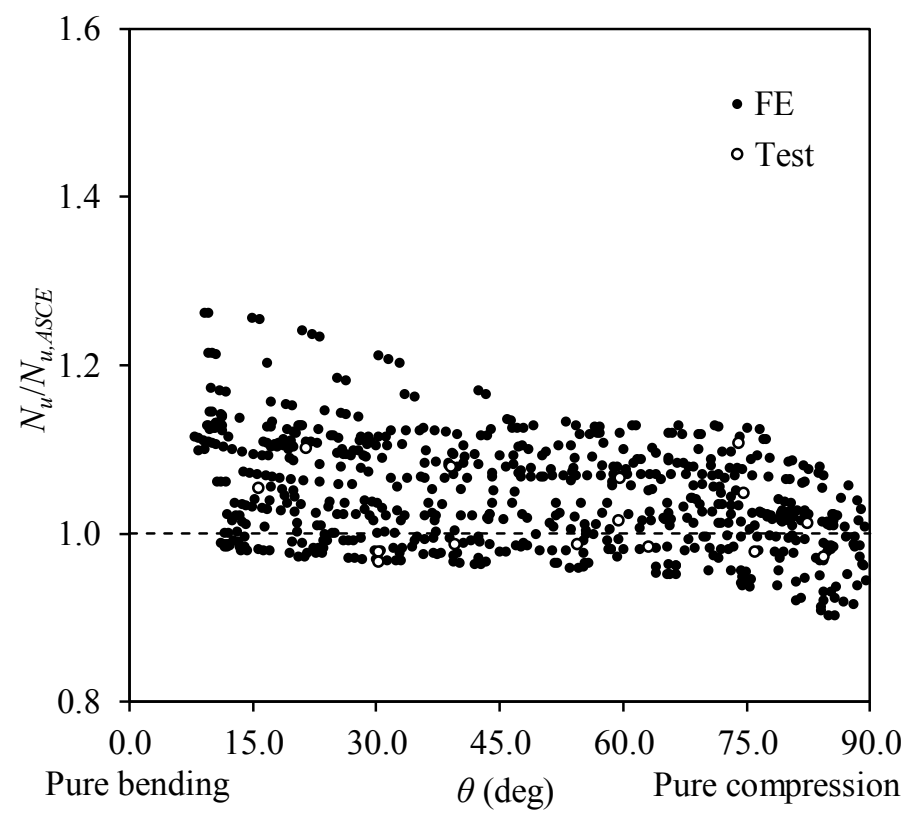

(b) SEI/ASCE-8.

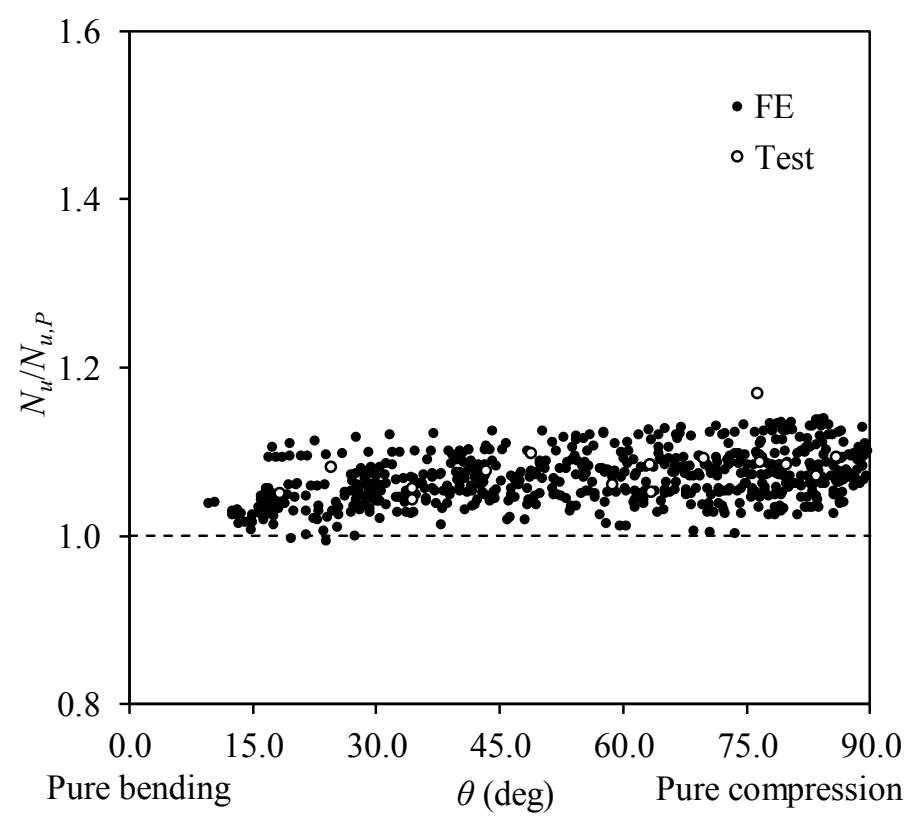

(d) Proposed approach.

Fig. 10. Comparison of duplex stainless steel beam-column test and FE results with predicted strengths. 


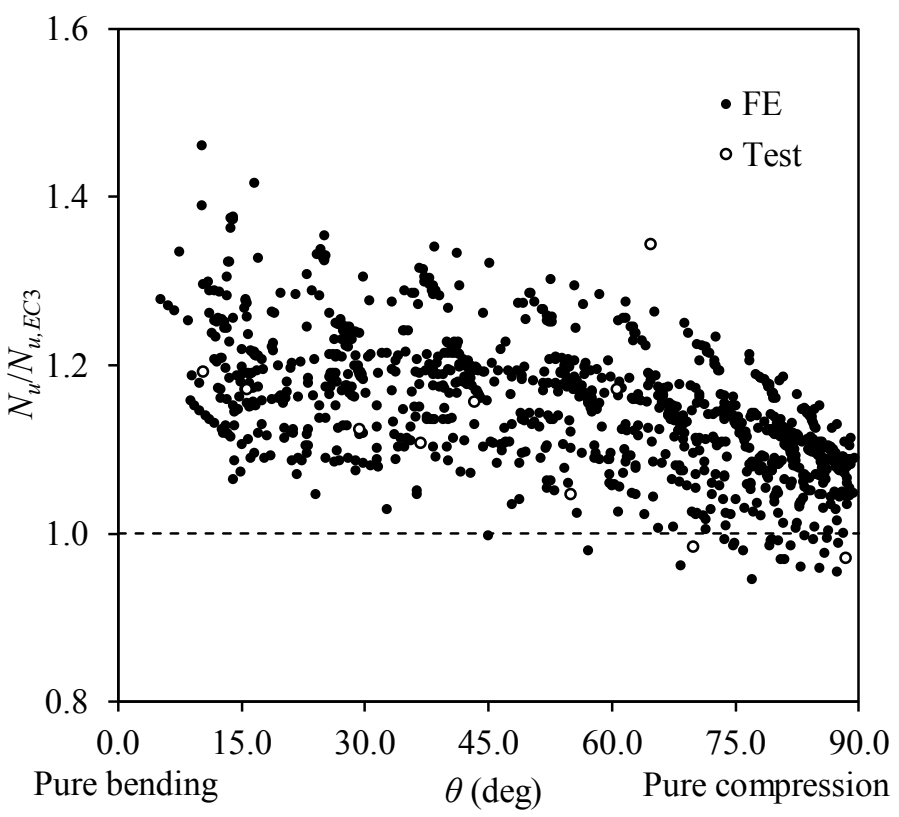

(a) EN 1993-1-4.

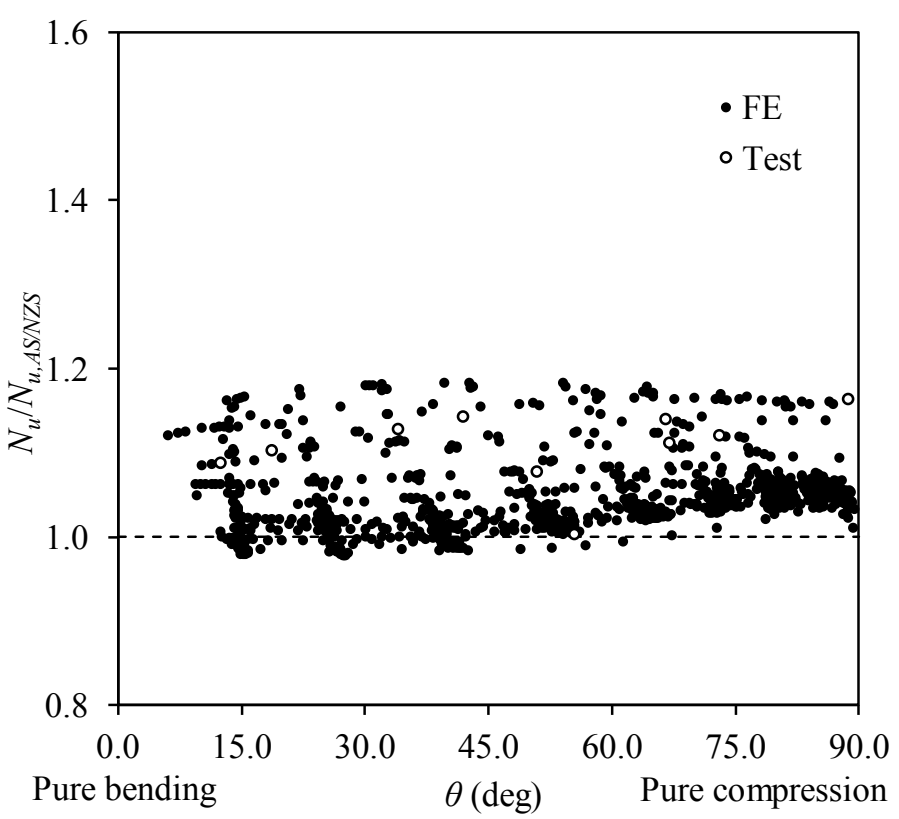

(c) AS/NZS 4673 .

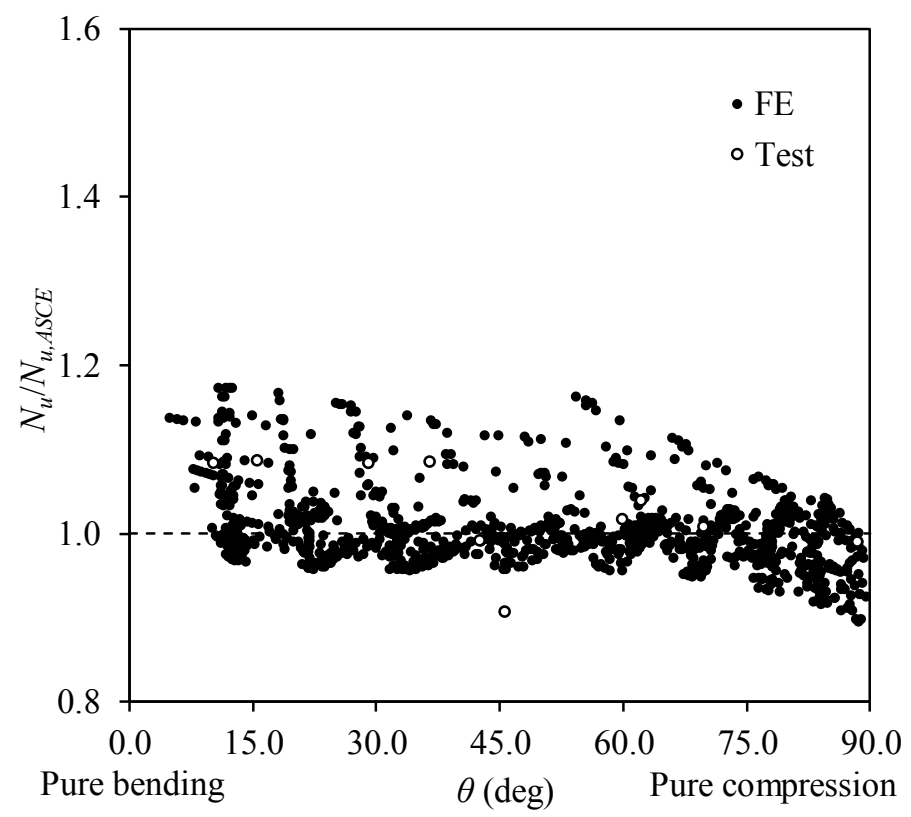

(b) SEI/ASCE-8.

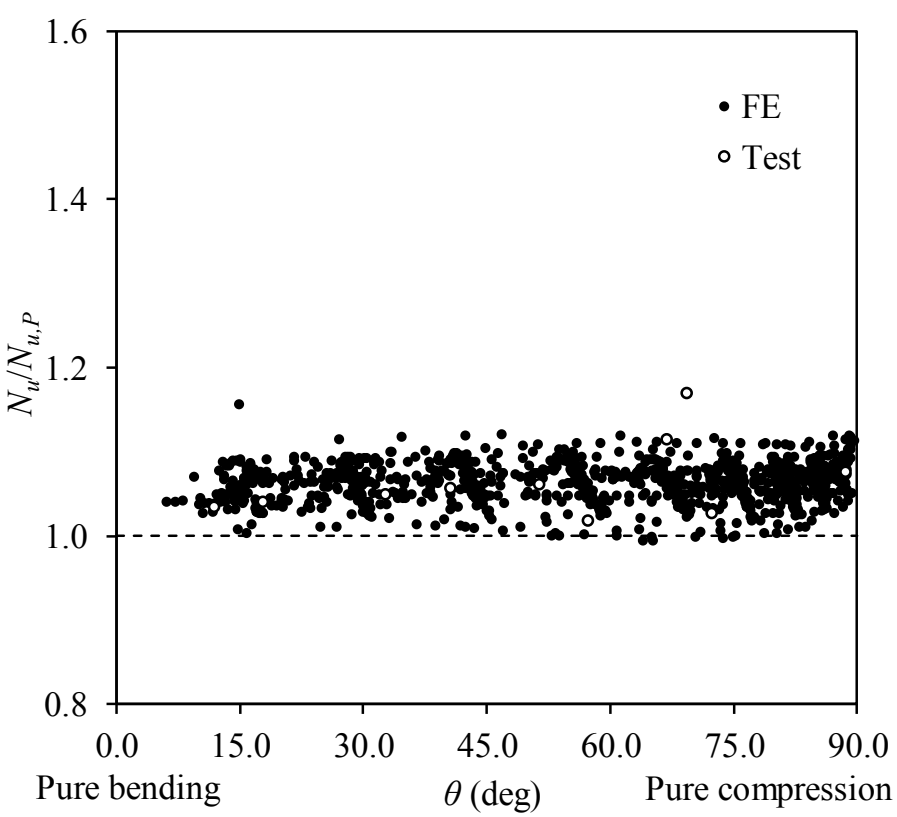

(d) Proposed approach.

Fig. 11. Comparison of ferritic stainless steel beam-column test and FE results with predicted strengths. 


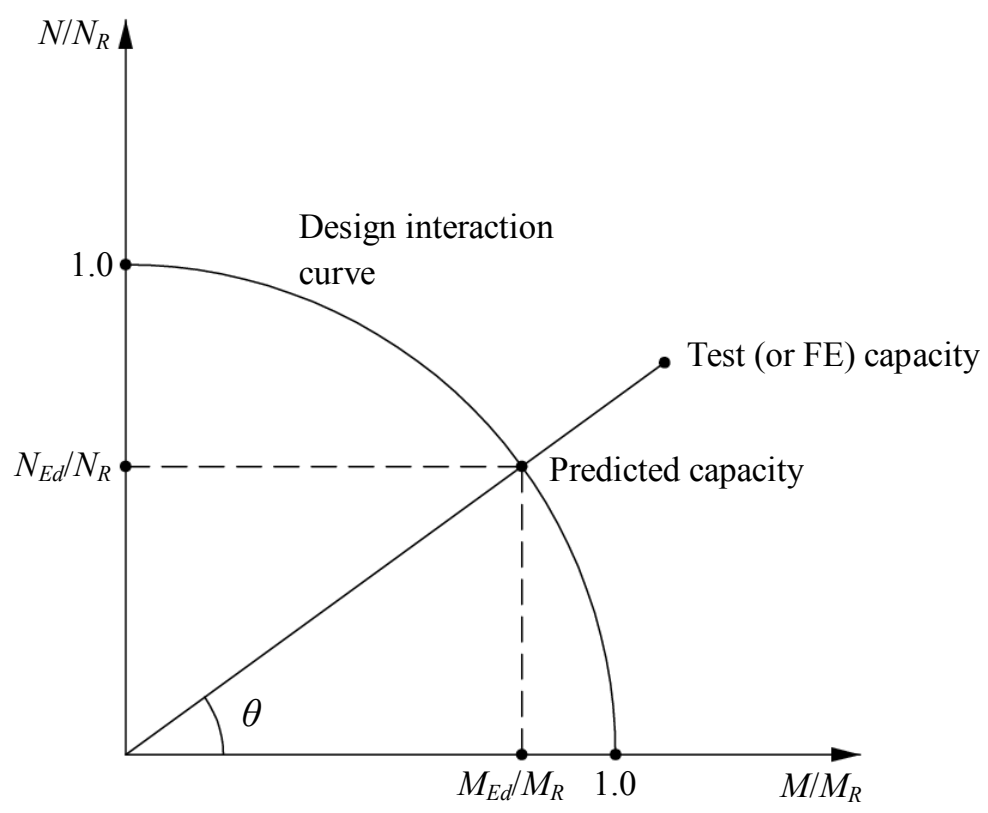

Fig. 12. Definition of $\theta$ on axial load-moment interaction curve. 


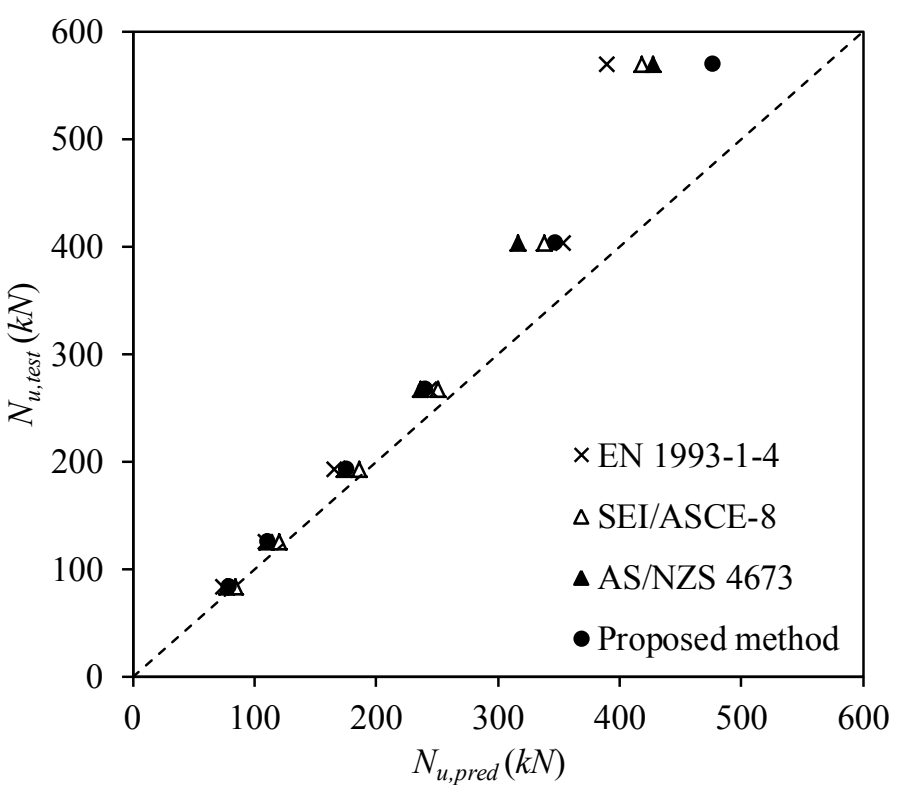

(a) Austenitic stainless steel.

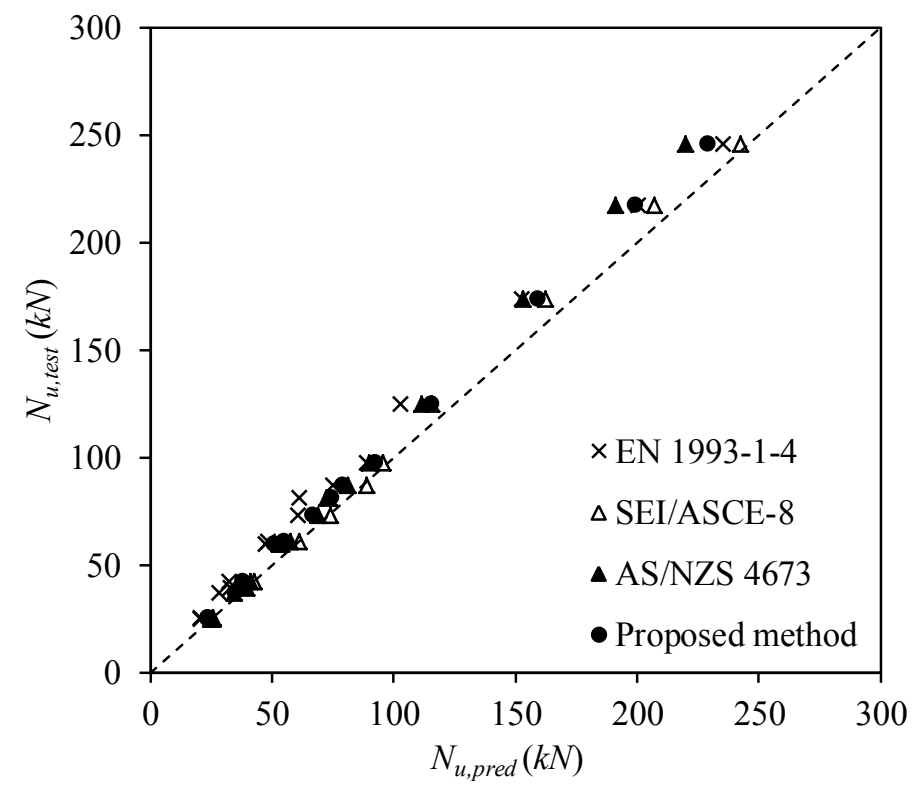

(b) Duplex stainless steel.

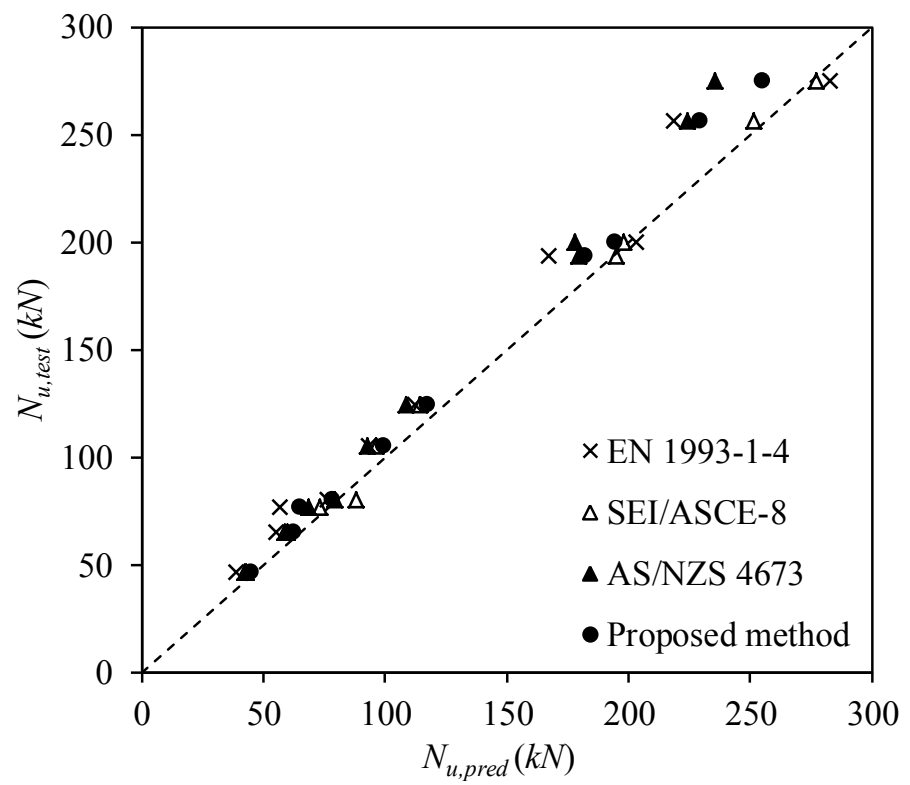

(c) Ferritic stainless steel.

Fig. 13. Comparisons of stainless steel beam-column test results with predicted strengths. 


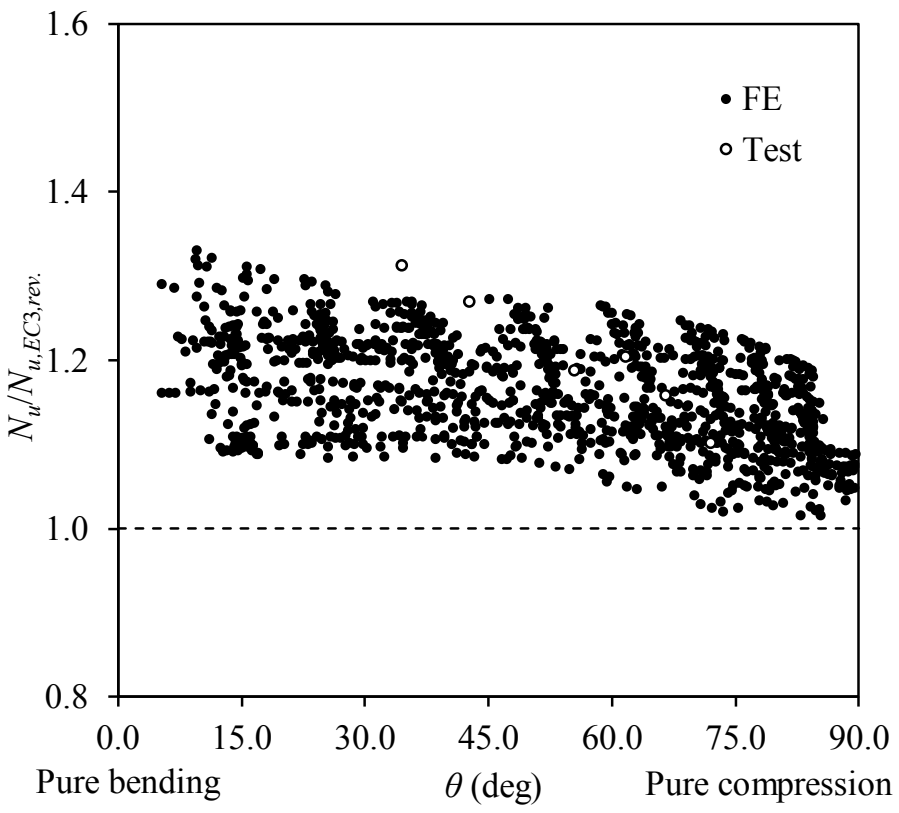

(a) Austenitic stainless steel.

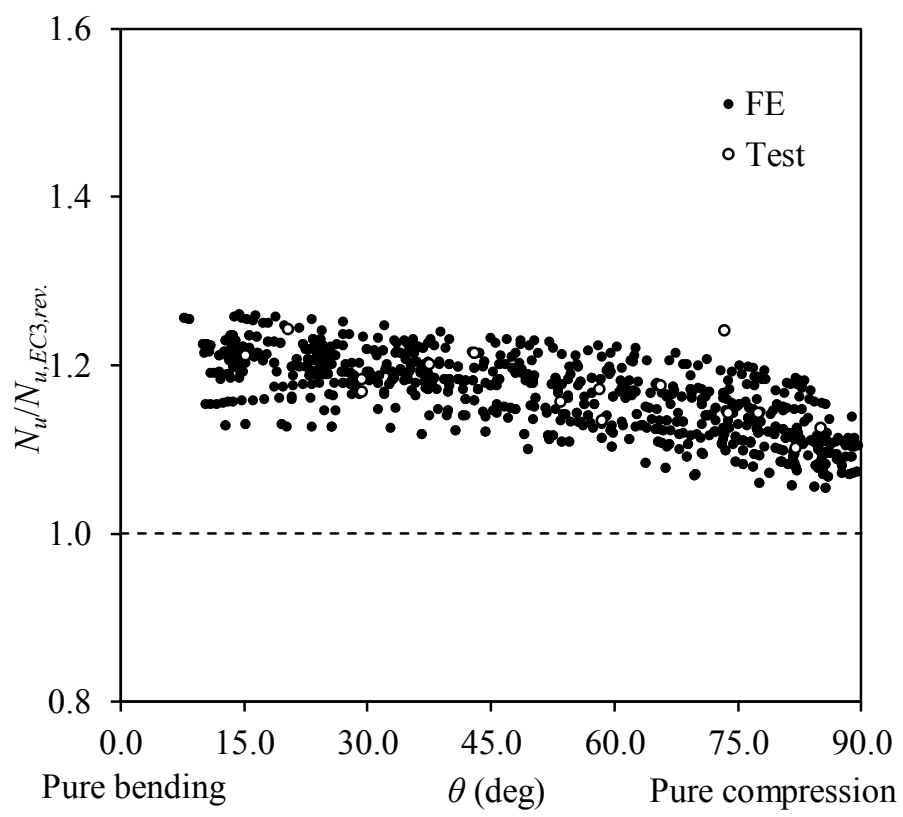

(b) Duplex stainless steel.

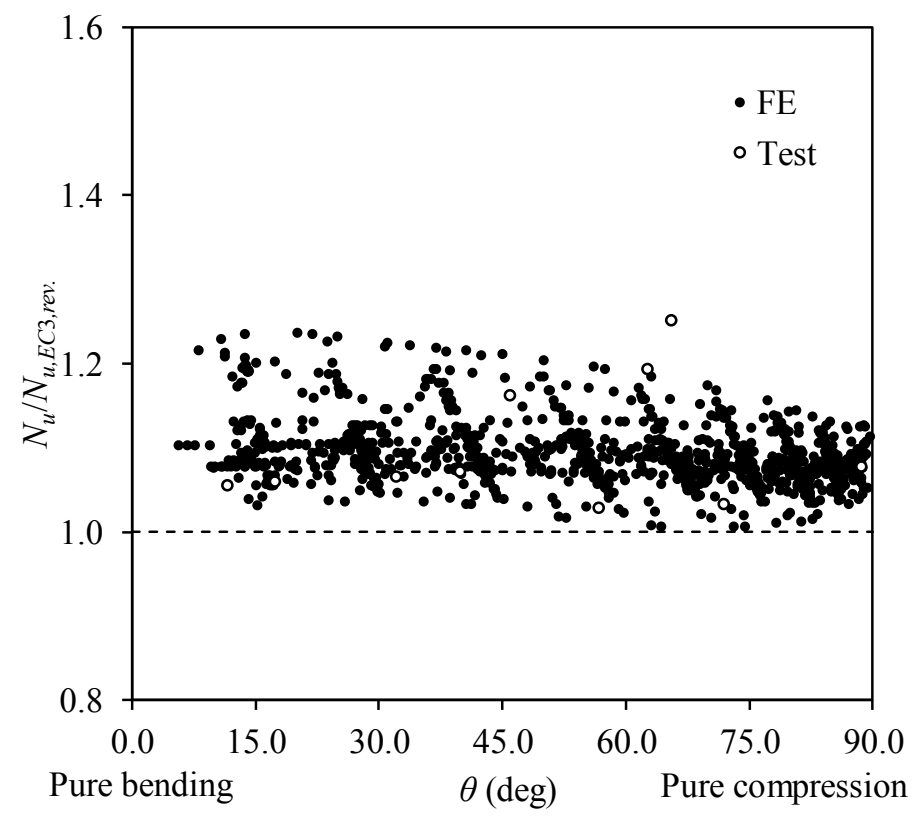

(c) Ferritic stainless steel.

Fig. 14. Comparisons of stainless steel beam-column test and FE results with predicted strengths from the revised EC3 approach. 
Table 1 Summary of key measured material properties from the tensile flat and corner coupons employed in the FE models.

(a) Flat material properties.

\begin{tabular}{lccccccc}
\hline Material grade & $E$ & $\sigma_{0.2}$ & $\sigma_{1.0}$ & $\sigma_{u}$ & \multicolumn{3}{c}{ R-O coefficient } \\
\cline { 6 - 9 } & $(\mathrm{GPa})$ & $(\mathrm{MPa})$ & $(\mathrm{MPa})$ & $(\mathrm{MPa})$ & $n$ & $n_{0.2,1.0}^{\prime}$ & $n_{0.2, u}^{\prime}$ \\
\hline Austenitic & 196 & 335 & 384 & 608 & 5.9 & 2.6 & 3.5 \\
Duplex & 198 & 635 & 694 & 756 & 6.0 & 3.2 & 4.2 \\
Ferritic & 199 & 470 & 485 & 488 & 7.3 & 7.6 & 10.9 \\
\hline
\end{tabular}

(b) Corner material properties.

\begin{tabular}{lccccccc}
\hline Material grade & $E$ & $\sigma_{0.2}$ & $\sigma_{1.0}$ & $\sigma_{u}$ & \multicolumn{3}{c}{ R-O coefficient } \\
\cline { 7 - 9 } & $(\mathrm{GPa})$ & $(\mathrm{MPa})$ & $(\mathrm{MPa})$ & $(\mathrm{MPa})$ & $n$ & $n_{0.2,1.0}^{\prime}$ & $n_{0.2, u}^{\prime}$ \\
\hline Austenitic & 201 & 559 & 622 & 725 & 4.8 & 3.9 & 4.1 \\
Duplex & 207 & 833 & 1053 & 1079 & 5.0 & 4.5 & 6.1 \\
Ferritic & 200 & 579 & - & 648 & 4.0 & - & 7.3 \\
\hline
\end{tabular}

Table 2 Geometric properties and cross-section slenderness of the modelled cross-sections.

\begin{tabular}{lcccccccc}
\hline Cross-section & Bending axis & $\begin{array}{c}B \\
\end{array}$ & & $H$ & $t$ & $r_{i}$ & \multicolumn{2}{c}{ Cross-section slenderness $\bar{\lambda}_{p}$} \\
\cline { 8 - 10 } & & $(\mathrm{mm})$ & $(\mathrm{mm})$ & $(\mathrm{mm})$ & $(\mathrm{mm})$ & Austenitic & Duplex & Ferritic \\
\hline RHS $200 \times 100 \times 8$ & MI & 100 & 200 & 8 & 8 & 0.50 & 0.62 & 0.53 \\
& MA & 100 & 200 & 8 & 8 & 0.26 & 0.32 & 0.28 \\
\hline RHS $200 \times 100 \times 10$ & MI & 100 & 200 & 10 & 10 & 0.39 & 0.50 & 0.42 \\
& MA & 100 & 200 & 10 & 10 & 0.21 & 0.26 & 0.22 \\
\hline
\end{tabular}

Note: MA and MI indicate bending about the major and minor axes, respectively.

Table 3 Proposed coefficients for interaction curves (Eq. (13)) for different material grades.

\begin{tabular}{cccc}
\hline Grade & $D_{1}$ & $D_{2}$ & $D_{3}$ \\
\hline Austenitic & 2.0 & 0.30 & 1.3 \\
Duplex & 1.5 & 0.40 & 1.4 \\
Ferritic & 1.3 & 0.45 & 1.6 \\
\hline
\end{tabular}


Table 4 Comparison of stainless steel SHS and RHS beam-column test and FE results with predicted strengths.

(a) Austenitic stainless steel.

\begin{tabular}{cccccc}
\hline $\begin{array}{c}\text { No. of tests: 6 } \\
\text { No. of FE simulations: } 1190\end{array}$ & $N_{u} / N_{u, E C 3}$ & $N_{u} / N_{u, A S C E}$ & $N_{u} / N_{u, A S / N Z S}$ & $N_{u} / N_{u, P}$ & $N_{u} / N_{u, E C 3, \text { rev. }}$ \\
\hline Mean & 1.16 & 1.02 & 1.12 & 1.07 & 1.15 \\
COV & 0.08 & 0.08 & 0.07 & 0.04 & 0.05 \\
\hline
\end{tabular}

(b) Duplex stainless steel.

\begin{tabular}{cccccc}
\hline $\begin{array}{c}\text { No. of tests: } 15 \\
\text { No. of FE simulations: } 900\end{array}$ & $N_{u} / N_{u, E C 3}$ & $N_{u} / N_{u, A S C E}$ & $N_{u} / N_{u, A S / N Z S}$ & $N_{u} / N_{u, P}$ & $N_{u} / N_{u, E C 3, \text { rev. }}$ \\
\hline Mean & 1.22 & 1.05 & 1.09 & 1.06 & 1.16 \\
COV & 0.07 & 0.06 & 0.05 & 0.03 & 0.04 \\
\hline
\end{tabular}

(c) Ferritic stainless steel.

\begin{tabular}{cccccc}
\hline $\begin{array}{c}\text { No. of tests: } 10 \\
\text { No. of FE simulations: } 1000\end{array}$ & $N_{u} / N_{u, E C 3}$ & $N_{u} / N_{u, A S C E}$ & $N_{u} / N_{u, A S / N Z S}$ & $N_{u} / N_{u, P}$ & $N_{u} / N_{u, E C 3, \text { rev. }}$ \\
\hline Mean & 1.15 & 1.01 & 1.06 & 1.06 & 1.09 \\
COV & 0.07 & 0.05 & 0.04 & 0.02 & 0.04 \\
\hline
\end{tabular}


Table 5 Comparison of stainless steel SHS and RHS beam-column test results with predicted strengths.

(a) Austenitic stainless steel.

\begin{tabular}{cccccc}
\hline No. of tests: 6 & $N_{u, \text { test }} / N_{u, E C 3}$ & $N_{u, \text { test }} / N_{u, A S C E}$ & $N_{u, \text { test }} / N_{u, A S / N Z S}$ & $N_{u, \text { test }} / N_{u, P}$ & $N_{u, \text { test }} / N_{u, E C 3, \text { rev. }}$ \\
\hline Mean & 1.18 & 1.11 & 1.17 & 1.12 & 1.19 \\
COV & 0.12 & 0.13 & 0.09 & 0.05 & 0.06 \\
\hline
\end{tabular}

(b) Duplex stainless steel.

\begin{tabular}{cccccc}
\hline No. of tests: 15 & $N_{u, \text { test }} / N_{u, E C 3}$ & $N_{u, \text { test }} / N_{u, A S C E}$ & $N_{u, \text { test }} / N_{u, A S / N Z S}$ & $N_{u, \text { test }} / N_{u, P}$ & $N_{u, \text { test }} / N_{u, E C 3, \text { rev. }}$ \\
\hline Mean & 1.19 & 1.02 & 1.07 & 1.08 & 1.17 \\
COV & 0.07 & 0.05 & 0.05 & 0.03 & 0.04
\end{tabular}

(c) Ferritic stainless steel.

\begin{tabular}{cccccc}
\hline No. of tests: 10 & $N_{u, \text { test }} / N_{u, E C 3}$ & $N_{u, \text { test }} / N_{u, A S C E}$ & $N_{u, \text { test }} / N_{u, A S / N Z S}$ & $N_{u, \text { test }} / N_{u, P}$ & $N_{u, \text { test }} / N_{u, E C 3, \text { rev. }}$ \\
\hline Mean & 1.13 & 1.03 & 1.11 & 1.06 & 1.10 \\
COV & 0.10 & 0.06 & 0.04 & 0.04 & 0.07 \\
\hline
\end{tabular}

Table 6 Reliability analysis results calculated according to EN 1990.

(a) Proposed design method

\begin{tabular}{ccccccc}
\hline Grade & No. of tests and FE simulations & $k_{d, n}$ & $b$ & $V_{\delta}$ & $V_{r}$ & $\gamma_{M 1}$ \\
\hline Austenitic & 1196 & 3.098 & 1.058 & 0.036 & 0.086 & 0.95 \\
Duplex & 915 & 3.101 & 1.055 & 0.027 & 0.064 & 1.05 \\
Ferritic & 1010 & 3.100 & 1.055 & 0.022 & 0.071 & 0.98 \\
\hline
\end{tabular}

(b) Revised EC3 design approach

\begin{tabular}{ccccccc}
\hline Grade & No. of tests and FE simulations & $k_{d, n}$ & $b$ & $V_{\delta}$ & $V_{r}$ & $\gamma_{M 1}$ \\
\hline Austenitic & 1196 & 3.098 & 1.121 & 0.053 & 0.095 & 0.92 \\
Duplex & 915 & 3.101 & 1.131 & 0.041 & 0.071 & 1.00 \\
Ferritic & 1010 & 3.100 & 1.074 & 0.036 & 0.076 & 0.98 \\
\hline
\end{tabular}

